\title{
1 Carbonation of calcium-magnesium pyroxenes: Physical-chemical \\ 2 controls and effects of reaction-driven fracturing
}

4 Monasterio-Guillot, L. ${ }^{*}{ }^{*}$, Fernandez-Martinez, A. ${ }^{2}$, Ruiz-Agudo, E. ${ }^{1}$ and Rodriguez-Navarro, C. ${ }^{1}$

$5 \quad{ }^{1}$ Univ. of Granada, Department of Mineralogy and Petrology, 18071, Granada, Spain

$6{ }^{2}$ Univ. Grenoble Alpes, Univ. Savoie Mont Blanc, CNRS, IRD, IFSTTAR, ISTerre, 38000

7 Grenoble, France

$8 \quad *$ Corresponding author: luismonasterio@ugr.es

\section{ABSTRACT}

10 The weathering of primary silicates, and their carbonation in particular, is key for the geochemical

11 cycling of elements, strongly affecting the $\mathrm{C}$ cycle and the long-term regulation of the Earth's

12 climate. The knowledge on the controlling factors and mechanisms of aqueous carbonation of

13 primary silicates is however still far from complete. This precludes a better understanding of their

14 chemical weathering in nature and is a strong handicap to implement effective Carbon Capture and

15 Storage (CCS) strategies. Here, dissolution-carbonation reactions of two abundant $\mathrm{Ca}-\mathrm{Mg}$ 16 pyroxenes, augite and diopside, have been investigated in experiments conducted at hydrothermal

17 conditions, in the presence/absence of different carbonate sources $\left(\mathrm{NaHCO}_{3}\right.$ and $\left.\mathrm{Na}_{2} \mathrm{CO}_{3}\right)$. We

18 show that the main reaction products are low-magnesium calcite and amorphous silica. A higher

19 conversion of augite $(\sim 38 \mathrm{wt} \%)$ than diopside $(\sim 15 \mathrm{wt} \%)$ was achieved. The presence of abundant

$20 \mathrm{Fe}$ and $\mathrm{Al}$ (and minor $\mathrm{Na}$ ) in the former pyroxene strongly enhances the release of cations to the

21 solution, and contributes to the formation of abundant secondary crystalline silicates as well as 
22 carbonates (Na-phillipsite and magnesium silicate hydrate, MSH). In particular, Na-phillipsite

23 nucleates in etch pits exerting a crystallization pressure $100 \mathrm{MPa}$ exceeding the tensile strength of 24 augite and causing extensive fracturing. This takes place via an interface-coupled dissolution-

25 precipitation mechanism, despite the bulk system being undersaturated with respect to this phase.

26 Limited reaction-induced fracturing was also observed following MSH precipitation within diopside

27 crystals. Reaction-induced fracturing increases exposed reactive surface area and creates channels

28 for solution flow, thereby contributing to the progress of the reaction via a positive feedback loop.

29 Ultimately, our results help to understand differences in the kinetics and mechanisms of chemical

weathering of these two abundant rock forming inosilicates relevant for CCS strategies, showing

31 that secondary phase formation (other than carbonates) are fostered by moderately alkaline $\mathrm{pH}$ and

32 the presence of alkali metals, resulting in reaction-driven fracturing that enables the progress of

33 silicate carbonation for an effective, safe, and permanent $\mathrm{CO}_{2}$ mineral storage. We also show that

34 under our experimental conditions the precipitation of amorphous silica and calcite cannot generate

35 sufficient pressure as to create fracturing, an effect that limits carbonation of $\mathrm{Mg}-\mathrm{Ca}-\mathrm{Fe}$ pyroxenes.

\section{INTRODUCTION}

Weathering of primary silicate minerals caused by a range biogeochemical processes

contributes to Earth's surface modeling, soil formation, the development of biota by supplying key nutrients (Nagajyoti et al., 2010) and the control of Earth's climate over geologic time-scales by the mineralization of $\mathrm{CO}_{2}$ via carbonation (Walker et al. 1981; Pacala and Socolow, 2004). Carbonation of primary silicates is a key step in the carbon cycle and follows a "Urey-type" reaction (Urey, 1952; Daval et al., 2009a; Di Lorenzo et al., 2018; Monasterio-Guillot et al., 2019),

$$
\mathrm{MSiO}_{3}+\mathrm{CO}_{2}+\mathrm{H}_{2} \mathrm{O}=\mathrm{MCO}_{3}+\mathrm{SiO}_{2} \cdot \mathrm{nH}_{2} \mathrm{O}
$$


which in the case of mafic and ultramafic minerals can be expressed by the more general reaction

46 (Daval et al., 2009a),

$$
\mathrm{M}_{x} \mathrm{Si}_{y} \mathrm{O}_{x+2 y-t}(\mathrm{OH})_{2 t}+x \mathrm{CO}_{2}=x \mathrm{MCO}_{3}+y \mathrm{SiO}_{2}+t \mathrm{H}_{2} \mathrm{O}
$$

48 where $\mathrm{M}$ is an alkaline-earth metal such as $\mathrm{Ca}^{2+}, \mathrm{Mg}^{2+}$, or a divalent transition metal (e.g., $\mathrm{Fe}^{2+}$ ).

49 These reactions highlight the key role of calcium- and magnesium-rich mafic and ultramafic rocks in Earth's climate control (Schott et al., 1981; Berner and Caldeira, 1997).

Due to the alarming rising levels of anthropogenic $\mathrm{CO}_{2}$ emissions to the atmosphere, principally caused by fossil fuel combustion, several initiatives have been developed for ex situ and in situ Carbon Capture and Storage (CCS). In this context, Geological Carbon Storage (GCS) via mineralization of $\mathrm{CO}_{2}$ after its deep injection into mafic and ultramafic geologic formations (e.g., CarbFix pilot test, Iceland; Matter et al., 2016) is a promising strategy (Lackner et al., 1995; IPCC, 2014). This in situ CCS strategy can be considered the safest and most permanent way to store this greenhouse gas (Seifritz, 1990). In terms of ex situ mineral carbonation, the most promising strategies are aqueous-based mineral carbonation processes, such as the "pH swing" method (Park and Fan, 2004), or the direct carbonation, normally achieved under circumneutral pH conditions (Oelkers and Cole, 2008; Daval et al., 2009a,b; Di Lorenzo and Prieto, 2017; Monasterio-Guillot et al., 2019), aided by complexing agents or biomimetic processes involving the use of carbonic anhydrase, silicates, or metal organic frameworks (MOFs) to enhance the dissolution-carbonation processes during mineral replacement (Di Lorenzo et al., 2018). precipitation process, whereby divalent cations are released to the solution and, in the presence of a Dissolved Inorganic Carbon (DIC) source, form secondary carbonate phases (Daval et al., 2009a,b).

67 Disclosing experimentally the key atomic- or molecular-scale processes and micro-to-macroscale 
mechanisms of these coupled dissolution-carbonation reactions is crucial to model, implement and enhance CCS processes and strategies, and to understand and model the fate of $\mathrm{CO}_{2}$ injected during GCS.

Several studies have focused on the fundamental understanding of the mechanisms involving dissolution of silicate minerals and the subsequent precipitation of carbonate phases (e.g., Casey et al., 1988; Banfield et al., 1995; Lackner et al., 1995; Ruiz-Agudo et al., 2012; Ruiz-Agudo et al., 2016; Di Lorenzo and Prieto, 2017; Monasterio-Guillot et al., 2019). Studies on the dissolution of primary silicates have systematically reported the formation of an amorphous and hydrated silica-rich layer covering the mineral's surface, the so-called "leached layer", surface altered layer (SALs) or amorphous silica-rich surface layer (ASSLs), which can passivate mineral dissolution (Casey et al., 1993; Daval et al., 2009a,b; Ruiz-Agudo et al., 2012; Hellmann et al., 2013; Ruiz-Agudo et al., 2016; Wild et al., 2019). Furthermore, most studies on the carbonation of primary silicates have reported an additional passivation effect caused by the formation of carbonate mineral coatings on the primary mineral surface, decreasing the porosity and the permeability of the starting material and limiting the progress of the reaction (O'Connor et al., 2005; Daval et al., 2009a,b; Kelemen et al., 2011). In general, passivation resulting in a reduction of permeability and porosity of the host material will take place due to precipitation of a more insoluble phase (Hellmann et al., 2012; Ruiz-Agudo et al., 2012; Wild et al., 2019). These effects play a critical role in GCS processes, controlling the dissolution rate of primary silicate materials and acting as a handicap for their effective $\mathrm{CO}_{2}$ mineralization (McGrail et al., 2006; Stockmann et al., 2008; Daval et al., 2009a,b; Ruiz-Agudo et al., 2012; Wild et al., 2019). However, the replacement of a mineral phase can involve precipitation of a secondary phase in a confined volume

90 of the host material (dissolution pits, pores, and/or micro-fractures), and this can generate 
strength of the host material resulting in fracturing of the parent phase, in turn increasing

93 permeability and exposing fresh reactive surface (Emmanuel and Ague, 2011). Reaction-driven

94 fracturing has been observed during hydration of olivine (Kelemen and Hirth, 2012; Plumper et al.,

95 2013; Lafay et al., 2018), in carbonation processes (Matter and Kelemen, 2009;; Kelemen et al.,

96 2011) and during weathering-related dissolution-precipitation replacement reactions involving

97 volume changes (positive or negative), tensile stress generation and collapse (Jamtveit et al., 2000;

98 Plümper et al., 2012; Røyne and Jamtveit, 2015). Positive volume changes and an associated stress

99 can also occur upon precipitation of amorphous phases in a confined space, as exemplified by

100 fracturing during alkali-silica reaction in cement (Rajabipour et al., 2015 and refs. therein).

101 However, in this latter case, fracturing is associated with hydration of the resulting silica gel

102 (incorporating different alkali and alkaline-earth metals). It is unknown, however, whether the latter

103 reaction-driven fracturing occurs during primary silicate carbonation.

Despite the recent progress in the understanding of the mechanisms and kinetics of

dissolution-carbonation of silicate minerals, the current knowledge regarding the effects of neutral to alkaline pH, carbonate speciation, secondary silicate formation ( Daval et al., 2009a; King et al., 2010; Sissmann et al., 2013; Monasterio-Guillot et al., 2019), with or without a passivation effect (i.e., the formation of an impervious layer of product phase on the parent phase) (Ruiz-Agudo et al., 2012; Ruiz-Agudo et al., 2016; Di Lorenzo et al., 2018; Wild et al., 2019), and its impact on porosity and permeability (Jamtveit et al., 2000; Kelemen et al., 2011; Royne and Jamtveit, 2015), is still far from complete. Moreover, most studies on silicate mineral carbonation have focused on 112 olivine (King et all., 2010; Daval et al., 2011), wollastonite (Di Lorenzo et al., 2018), or thermally activated serpentine (O'Connor et al., 2005), while very little attention has been paid to other 114 abundant primary silicates such as Mg-Ca-Fe pyroxenes (Stockmann et al., 2008, 2013; Bodor et 115 al., 2013). 
This study aims to determine experimentally the effects of $\mathrm{pH}$, DIC source, and carbon

117 speciation in solution under hydrothermal conditions on the carbonation of two of the most

118

119

120

121

122

123

124

125

126

127

128

129

130

131

132

133

134

135

136

137

138

139

abundant clinopyroxenes in the Earth's crust. In particular, we aim to shed light onto the effect of secondary silicate mineral formation during carbonation replacement, and their effect on reactiondriven fracturing (King et al., 2010; Kelemen et al., 2011; Lafay et al., 2018). Finally, we strive to gather mechanistic and geochemical results of relevance for CCS strategies, GCS in particular. To achieve these goals, we studied the dissolution-carbonation processes under near-neutral to moderately-alkaline $\mathrm{pH}$, of diopside $\left(\mathrm{CaMgSi}_{2} \mathrm{O}_{6}\right)$ and augite $\left(\left(\mathrm{Ca}, \mathrm{Mg}, \mathrm{Fe}^{2+}\right)_{2} \mathrm{Si}_{2} \mathrm{O}_{6}\right)$, two calcium and magnesium primary silicates of the group of pyroxenes, one of the most abundant groups of rock-forming minerals in the Earth's crust (Deer et al., 1966; Schott et al., 1981; Knauss et al., 1993). Pyroxenes are inosilicate minerals with a general formula $\mathrm{XYSi}_{2} \mathrm{O}_{6}$ where $\mathrm{X}$ represents $\mathrm{Na}^{+}$, $\mathrm{Ca}^{2+}, \mathrm{Mn}^{2+}, \mathrm{Fe}^{2+}, \mathrm{Mg}^{2+}$, and $\mathrm{Li}^{+,}$and $\mathrm{Y}$ represents $\mathrm{Mn}^{2+}, \mathrm{Fe}^{2+/ 3+}, \mathrm{Mg}^{2+}, \mathrm{Al}^{3+}, \mathrm{Cr}^{3+}$ (Morimoto, 1988; Schott et al., 1981). Diopside was chosen because dissolution of this mineral has been thoroughly studied (Berner et al., 1980; Schott et al., 1981; Knauss et al., 1993; McGrail et al., 2006; Dixit and Carroll, 2007; Stockmann et al., 2008), and a few studies have focused on its carbonation (Stockmann et al., 2013), so that it can be used as a reference clinopyroxene. In contrast, the dissolution of augite has been sparsely studied (McAdam et al., 2008; Stockmann et al., 2013), and there are no studies on its carbonation other than the very preliminary one by O'Connor et al (2005).

The original features of this study are: (i) in contrast to most silicate weathering and carbonation studies, the selected $\mathrm{pHs}$ of this work include a wide range of natural groundwater $\mathrm{pH}$ (6.5 - 8.5) (Driscoll, 1986), which helps to directly extrapolate our results to natural environments; (ii) to the best of our knowledge, this is the first study performed using high purity single crystals of these pyroxenes instead of powders of these minerals, thus allowing a detailed spatially-resolved characterization of dissolution-carbonation reactions using high-resolution techniques such as X-ray 
micro-computed tomography (Micro-CT); (iii) we combine dissolution-carbonation processes to

141 reveal and quantify experimentally the effect of crystallization stress of newly formed secondary

142 silicate phases on the progress of pyroxene carbonation.

\section{MATERIALS AND METHODS}

\subsection{Starting materials}

146 Augite and diopside crystal specimens, from science museum and undetermined localities, of 147 optical quality (i.e., high purity and transparent) were cut with a diamond saw into single crystals $1481 \times 1 \times 1 \mathrm{~mm}$ in size $(\sim 0.005 \mathrm{~g})$. Crystals were cut along $\{001\},\{100\}$ and $\{010\}$ planes as 149 corroborated by means of electron backscattering diffraction (EBSD) analysis using a field emission 150 scanning electron microscope (FESEM, Auriga Carl Zeiss SMT). The composition of diopside 151 crystals used in this study is $\mathrm{Ca}_{0.97} \mathrm{Mg}_{0.84} \mathrm{Fe}_{0.17} \mathrm{Si}_{2} \mathrm{O}_{6}$, whereas that of augite crystals is

$152 \mathrm{Na}_{0.05} \mathrm{Ca}_{0.86} \mathrm{Mg}_{0.76} \mathrm{Fe}_{0.23} \mathrm{Ti}_{0.07} \mathrm{Al}_{0.3} \mathrm{Si}_{1.7} \mathrm{O}_{6}$, as calculated from ICP-OES analysis after acid digestion 153 of the unreacted mineral (see details below). No minor phases were detected by X-ray diffraction 154 (XRD) in diopside crystals. However, rutile $\left(\mathrm{TiO}_{2}\right)$ traces were detected in the augite crystals (see 155 below).

\section{2.2. Hydrothermal experiments}

157 Two types of hydrothermal experiments were performed: (i) dissolution experiments in the absence 158 of added dissolved inorganic carbon (DIC), and (ii) carbonation experiments involving the addition 159 of DIC. Dissolution experiments were performed using $1 \mathrm{~mL}$ Milli-Q water (resistivity 18.2 $160 \mathrm{M} \Omega \cdot \mathrm{cm}$, Millipore) adjusted to $\mathrm{pH} 7.5$ using $\mathrm{NaOH}$ (Sical). Carbonation experiments were 161 performed in solutions prepared by mixing $1 \mathrm{~mL}$ Milli-Q water with $0.025 \mathrm{~g}$ of $\mathrm{NaHCO}_{3}(\mathrm{pH} 7.5)$, 
or $0.031 \mathrm{~g}$ of $\mathrm{Na}_{2} \mathrm{CO}_{3}$ ( $\mathrm{pH}$ of 11.5), to ensure an excess of carbonate and to achieve the desired $\mathrm{pH}$

163 values (i.e., $\mathrm{pH}=7.5$ and 11.5 ).

Single crystals $(\sim 0.022 \mathrm{mmol})$ were introduced in PTFE vessels (polytetrafluoroethylene,

$\mathrm{V}_{\text {tot }}=3 \mathrm{~mL}$ ) with $1 \mathrm{~mL}$ of the different solutions described above. Afterward, the PTFE vessels

were introduced into hydrothermal steel reactors, sealed and heated to $150^{\circ} \mathrm{C}$ for 7,14 and 28 days.

The pressure was not independently controlled and corresponds to the vapor pressure at the

experimental $T$. At the given time intervals, reactors were cooled at room $T$ and opened. Crystals

were separated and dried at room $T$. To ensure reproducibility, experiments were performed in

experiments were carried out (i.e. $\mathrm{NaHCO}_{3}, \mathrm{Na}_{2} \mathrm{CO}_{3}$ and water) and three different sampling times

Geochemical calculations and solution speciation were performed using PHREEQC

Appelo, 1990) to model the evolution of the Saturation Index $\left(\mathrm{SI}_{n}\right)$ and free energy $(\Delta \mathrm{G})$ of the

different precipitates identified in our experimental conditions. Due to the absence of geochemical information for augite in any database present in this PHREEQC version, information for this phase

179 was introduced manually following the geochemical data from Davidson and Lindsley (1985), 180 Loucks (1996), Palandri and Kharaka (2004) and Van Pham et al. (2012) $(\operatorname{logK}=21 ;-\Delta H=122.775$ $181 \mathrm{~kJ} / \mathrm{mol})$.

\subsection{Analysis of the solutions and solids}

183 The $\mathrm{pH}$ of the starting and reacted solutions was measured using a glass electrode (Metrohm) 184 calibrated with three standard solutions $\left(\mathrm{pH}=4.01,7.01\right.$ and 10.01 at $\left.25^{\circ} \mathrm{C}\right)$ with \pm 0.01 of 
uncertainty. The concentration of $\mathrm{Ca}, \mathrm{Mg}$ and $\mathrm{Si}$ in reacted solutions was determined by ICP-OES at Centro de Instrumentación Científica (CIC-UGR, Perkin Elmer, Optima 8300) and at Institut de Sciences de la Terre (ISTerre, Varian 720ES).

In order to determine the mineralogical/structural changes undergone by the reacted samples, they were analyzed using a JASCO IRT-7100 microscope coupled to a Micro-Raman spectrometer ( $\mu$-Raman, JASCO NRS-5100) with a Nd-YAG laser $(\lambda=785.11 \mathrm{~nm}, 30 \mathrm{~mW}$,

191 Elforlight G4-30), spectral range 1200-100 $\mathrm{cm}^{-1}$. Reported spectra correspond to the average of 5 measurements.

The morphology, texture and composition of solids were characterized by scanning electron microscopy (SEM, FEI Quanta 400) coupled to an X-ray energy dispersive spectrometer (EDS, xFlash Bruker) for chemical microanalysis, working at an acceleration voltage of $20 \mathrm{kV}$.

Samples reacted for 28 days were analyzed by high-resolution X-ray Micro-Computed Tomography (Micro-CT, VERSA Xradia 510, ZEISS) to disclose and quantify the spatial distribution of reactant and product phases and cracks. Scans were performed at $40 \mathrm{kV}$ and $75 \mu \mathrm{A}$. Data were acquired with a 4x magnification objective and a charge coupled device (CCD) sensor for a total scan time of $15 \mathrm{~h}$ including the collection of reference images. The voxel size achieved under these conditions was $3 \mu \mathrm{m}$. Analyses of Micro-CT were performed on the same crystals first analyzed by SEM-EDX to avoid any potential error on the selection of the grey-level/contrast threshold to quantify the selected phases. The image analysis was performed using the ImageJ software (Schneider et al., 2012) and Dragonfly software (Version 4.1, Object Research Systems).

Finally, all reacted crystals were thoroughly crushed using an agate mortar (grain size $<200$ 206 $\mu \mathrm{m})$ and analyzed by X-Ray Diffraction (XRD) using an X'Pert PRO diffractometer (PANalytical) with the following instrumental parameters: $\mathrm{Cu} \mathrm{K} \alpha$-radiation $(\lambda=1.5405 \AA), 40 \mathrm{~mA}$ current, $45 \mathrm{kV}$ 
tension, $3-70^{\circ} 2 \theta$ measurement range, 4 s per step, and $0.04^{\circ} 2 \theta$ step size. Prior to analysis, powder samples were placed on zero-background Si sample holders. Diffraction patterns were analyzed using the computer software HighScore Plus 2.2.4 (PANalytical) and minerals were identified matching the experimental diffraction peaks with those included in the Joint Committee for Powder Diffraction Standards (JCPDS) PDF-2 database. For the quantification of the crystalline products, we used the Rietveld method (Rietveld, 1969) and the crystal structures provided by the American Mineralogist Crystal Structure Database (Table S1) using HighScore Plus 2.2.4 (PANalytical). To corroborate the accuracy of the XRD Rietveld quantification, the normalized extent of carbonation $\left(\xi_{\mathrm{n}}\right)$ was calculated for Rietveld analyses and for mass balance analyses using the equation (Daval et al. 2009b):

$$
\xi_{n}=\left(x_{C a l} / M_{c a l}\right) /\left(x_{p y} / M_{p y}+x_{c a l} / M_{c a l}\right)
$$

where $x_{C a l}$ and $x_{p y}$ are the wt $\%$ of calcite and pyroxene (diopside or augite) determined by Rietveld analysis or mass balance calculation, and $M_{c a l}$ and $M_{p y}$ are the molecular masses $\left(\mathrm{g} \cdot \mathrm{mol}^{-1}\right)$ of calcite and pyroxenes respectively, yielding dimensionless $\xi_{\mathrm{n}}$.

To calculate the amount of Si-bearing amorphous phases obtained after 28 days of reaction, mass balance calculations were performed using the data obtained by Rietveld analysis of reacted solids and the results of ICP-OES chemical analysis of solutions, as follows:

$$
\Delta m=m_{p y r}-\left(m_{s o l}+m_{p h i}\right)
$$

226 where $m_{p y r}$ is the molar \% of Si from the reacted (dissolved) pyroxene obtained from the Rietveld analyses and the values of the initial mass of pyroxene in the experiments, $m_{s o l}$ is the molar $\mathrm{Si}$ 228 concentration in solution obtained by ICP-OES analyses and $m_{p h i}$ is the molar \% of Si precipitated 229 in the Na-phillipsite phase obtained by Rietveld analysis. A detailed description of the mass balance 
calculations is presented in Supplementary Material. Note that Na-phillipsite is the only crystalline

231 secondary silicate that we could identify in our runs. The difference in concentration obtained, $\Delta m$,

232 is interpreted here as the Si contained in the Si-bearing amorphous phases (amorphous silica and 233 magnesium silicate hydrate, see below).

234 Selected crystals were analyzed to identify amorphous phases by Fourier transform infrared 235 spectroscopy using an attenuated total reflectance sample holder (ATR-FTIR, Jasco), spectral range $2364000-400 \mathrm{~cm}^{-1}$, and step size of $0.48 \mathrm{~cm}^{-1}$. Reported spectra correspond to the average of 72 237 measurements.

\section{RESULTS}

\subsection{Evolution of solution chemistry during dissolution-carbonation experiments}

240 In all systems studied here, augite runs systematically presented a higher release of $\mathrm{Ca}, \mathrm{Mg}$ and $\mathrm{Si}$ 241 to the solution as compared to diopside runs (Figure 1).

\subsubsection{Evolution of the solution chemistry in water runs}

In water (initial $\mathrm{pH}$ 7.5) significant amounts of alkaline-earth metals were released from both pyroxenes and remained in solution after 28 days of reaction (Figure 1a-d), an effect that can be related to the relatively large extent of dissolution of the starting material and the very limited DIC source (i.e., $\mathrm{CO}_{2}$ present in the head space $\left(1.2 \mathrm{~cm}^{3}\right)$ of the reactor). A slight decrease in the total

247 concentration of $\mathrm{Ca}$ and $\mathrm{Mg}$ at 14 days, followed by a further increase was observed in water experiments, while the $\mathrm{pH}$ increased up to 14 days and subsequently decreased $(\mathrm{pH} 8.6$ in augite and $\mathrm{pH} 9$ in diopside runs). These results suggest that, after an initial period of pyroxene dissolution, $\mathrm{Ca}-\mathrm{Mg}$ bearing carbonates formed within 14 days (corroborated by the analysis of reacted solids, see section 3.2). Precipitation of carbonates releases protons (O’Connor et al., 2005;

252 Rodriguez-Navarro et al., 2015), causing a decrease in $\mathrm{pH}$ and, therefore, a renewed dissolution of 
253 the primary silicate to feed cations to the solution. If only $\mathrm{Mg}$-Ca carbonate were precipitated, $\mathrm{Si}$ in

254 solution should display a constant increase due to the two dissolution steps. However, Figures 1e

255 and 1f show that in the case of diopside runs, $\mathrm{Si}$ in solution showed a constant concentration during

256 the whole experimental runs, whereas in augite systems, the concentration of Si presented an initial

257 plateau between 7 and 14 days, matching the $\mathrm{pH}$ rise, and a later increase with a $\mathrm{pH}$ decrease. We

258 suggest that in both runs, formation of amorphous silica $\left(\mathrm{SiO}_{2 \mathrm{am}}\right)$ took place, which is consistent

259 with previous works on pyroxene dissolution (Schott et al., 1981; Dixit and Carroll, 2007; McAdam

260 et al., 2008). Time-resolved variations in Si concentration during augite dissolution should be

261 explained by the precipitation of an additional Si-bearing phase (Na-Phillipsite, Figure 1e) that

262 fostered further release of Si from the parent phase.

\subsubsection{Evolution of the solution chemistry in $\mathrm{NaHCO}_{3}$ runs}

Ca release to the solution from both pyroxenes in $\mathrm{NaHCO}_{3}$ runs presented a first increase

until 14 days, less pronounced in diopside runs, and a subsequent decrease caused by the precipitation of secondary Ca-bearing phases, as corroborated by XRD (see section 3.3). Mg release in augite runs showed a slight increase after 14 days of reaction. Logarithmic scale was used to unravel time differences (Figure S1). It can be observed a decrease up to 14 days and a further increase after 28 days of reaction. However, due to measurement error, we cannot infer a real increase or a more stable behavior. For this reason, we assume, in agreement with XRD results (Figure S9 and S11), a constant release of $\mathrm{Mg}$ from augite and the subsequent formation of a Ca-Mg secondary phase. In the case of diopside, the release of $\mathrm{Mg}$ showed a decreasing trend between 7 and 28 days in logarithmic scale (Figure S1), not observable using a linear scale figure (Figure 1). It can be assumed a constant sink of $\mathrm{Mg}$, probably caused by the precipitation of $\mathrm{Mg}$-calcite. The Si concentration in solution in $\mathrm{NaHCO}_{3}$ systems was the lowest measured in this work as compared with the $\mathrm{Na}_{2} \mathrm{CO}_{3}$ and water runs, suggesting an important precipitation of Si-bearing secondary 
277 phases. It must be noted that the starting $\mathrm{pH}$ was the same in water and $\mathrm{NaHCO}_{3}$ solutions,

278 however, water systems underwent a higher $\mathrm{pH}$ increase over the first 14 days of reaction. We

279 hypothesize that the higher level of carbonate precipitation in $\mathrm{NaHCO}_{3}$ runs and the associated

280 higher proton release led to such a limited $\mathrm{pH}$ rise in this run.

\subsubsection{Evolution of the solution chemistry in $\mathrm{Na}_{2} \mathrm{CO}_{3}$ runs}

In $\mathrm{Na}_{2} \mathrm{CO}_{3}$ runs, the concentration of $\mathrm{Si}$ in solution was up to two orders of magnitude

higher than in the other systems. This result is consistent with the $\mathrm{pH}$-dependent solubility of silica,

et al., 2019). Interestingly, the Si concentration in augite runs was higher than in diopside runs. This bearing phase formed in diopside runs.

\subsubsection{Evolution of the dissolution rates of pyroxenes}

289

290

291

292
Dissolution rates of pyroxenes were calculated based on $\mathrm{Si}$ concentration in solution at the three sampling times (Figure S2). All our results show rates (LogR from -10.5 down to -13 ) that are in partial agreement with those reported in the literature ( $\operatorname{LogR}$ from -9 down to $-11 \mathrm{~mol}^{-2} \mathrm{~m}^{-1}$ ) (Daval et al. 2010; Dixit and Carroll 2007). Yet they were systematically lower, especially in the case of $\mathrm{NaHCO}_{3}$ runs where our rates were two order of magnitude lower. This shows that in our closed system we were closer to equilibrium than in other studied systems (flow-through experiments). Our results are also consistent with the fact that we have precipitation of siliconcontaining secondary phases, which reduced the silicon content in solution, and as a consequence, the values of $\log R$.

\subsection{Characterization of solids reacted in water}


301 XRD patterns showed small changes after reaction of augite with water for 28 days (Figure 2a).

302 Rietveld analyses (Figure 2b) showed less than $15 \mathrm{wt} \%$ of augite replacement by: low Mg-calcite 303 (2.61 wt\%), Na-phillipsite $(\sim 11 \mathrm{wt} \%)$ and iron oxides (hematite, $2.16 \mathrm{wt} \%)$. Na-phillipsite is a 304 zeolite composed by $\mathrm{Na}, \mathrm{Al}$ and $\mathrm{Si}$, with the possibility of $\mathrm{Mg}, \mathrm{Ca}$ and $\mathrm{K}$ incorporation (theoretical 305 formula: $\left.(\mathrm{Na}, \mathrm{K}, \mathrm{Ca})_{1-2}(\mathrm{Si}, \mathrm{Al})_{8} \mathrm{O}_{16} \cdot 6 \mathrm{H}_{2} \mathrm{O}\right)$. Hematite was also present from the early stages of reaction, showing a continuous but minor increase in concentration over time due to Fe release from the parent phases and the decrease in the solubility of iron oxides and hydroxides with increasing pH (Schwertmann, 1991) causing fast precipitation. $\mu$-Raman analyses confirmed the precipitation of calcite (Figure 2c) showing the translational lattice mode (T) at $286 \mathrm{~cm}^{-1}$, the $\mathrm{v}_{4}$-Symmetric $\mathrm{CO}_{3}$ deformation at $717 \mathrm{~cm}^{-1}$ and the $\mathrm{v}_{1}$-symmetric $\mathrm{CO}_{3}$ stretching band at $1085 \mathrm{~cm}^{-1}$ (Gunasekaran et al., 2006). Hematite was also identified by $\mu$-Raman showing bands at $326 \mathrm{~cm}^{-1}, 449 \mathrm{~cm}^{-1}$ and 570 $\mathrm{cm}^{-1}$ corresponding to hematite $\mathrm{E}_{\mathrm{g}}, \mathrm{E}_{\mathrm{u}}$, and $\mathrm{E}_{\mathrm{g}}$ vibrations, respectively (Bersani et al., 1999;

313 Chamritski and Burns, 2005). SEM-EDS analysis of augite crystals reacted for 28 days showed fractures filled by a secondary Na-rich silicate, Na-phillipsite as demonstrated by XRD analysis (Figure 1d-e and S1). EDS point analyses (Figure S4 and Table S2) confirmed the presence of this zeolite phase with empirical formula $\mathrm{Na}_{1.95} \mathrm{Mg}_{0.05} \mathrm{Al}_{3.21} \mathrm{Si}_{4.79} \mathrm{O}_{16} \cdot 6 \mathrm{H}_{2} \mathrm{O}$. Despite the lack of added DIC, a small amount of calcite was observed (Figure S5). The formation of calcite suggests that the $\mathrm{CO}_{2}$ present in the head space of the reactor $\left(1.2 \mathrm{~cm}^{3}\right)$ dissolved in the solution forming $\mathrm{HCO}_{3}{ }^{-}$, which upon dissociation, supplied $\mathrm{CO}_{3}{ }^{2-}$ ions that, in the presence of $\mathrm{Ca}^{2+}$ ions, caused the 320 precipitation of calcite and the release of $\mathrm{H}^{+}$. This is consistent with the $\mathrm{pH}$ and $\mathrm{Ca}^{2+}$ concentration evolution in solution analyses (Figure 1a and d). SEM-EDS analysis of calcite showed that this 322 phase included $\mathrm{Mg}$. To unravel the actual content of $\mathrm{Mg}$ in calcite, the lattice parameters of calcite 323 were calculated by Rietveld refinement and the $\mathrm{Mg}$ content was determined according to Goldsmith 
et al. (1958) (Table S3). The calculated $\mathrm{Mg}$ amount in calcite was 8 mol\%. Silica gel was also

325 identified by SEM-EDS analysis (Figure S6) in dissolving areas, such as small fractures and etch

326 pits. Micro-CT analysis showed the presence of two secondary phases (identified by their contrast

327 due to differences in X-ray attenuation), already identified in the same crystals using SEM-EDS. In

328 Figure 2f, the red phase is amorphous silica and the green one is Na-phillipsite. It can be observed

329 that precipitates were present inside the reacted crystals filling fractures that in some cases cross-cut

330 the whole pyroxene crystal. Image analysis of Micro-CT results showed $23 \mathrm{wt} \%$ augite replacement

331 by $14.3 \mathrm{wt} \%$ Na-phillipsite and $8.7 \mathrm{wt} \%$ amorphous silica. These values do not agree with the mass

332 balance for silicon calculated using Eq. (4): a deficit of Si in the solution was detected that should

333 be present as a precipitate. We suggest that the amorphous $\mathrm{SiO}_{2}$ content obtained from Micro-CT

334 analysis actually included calcite and amorphous silica due to the resolution constraints of the

335 Micro-CT equipment. Mass balance was recalculated using the values obtained by Micro-CT total

336 amount of augite dissolved and the concentration of $\mathrm{Si}$ and $\mathrm{Ca}$ in solution, yielding $2.16 \mathrm{wt} \% \mathrm{SiO}_{2}$

337 and $2.61 \mathrm{wt} \%$ calcite. If we normalize the phase contents obtained by Rietveld analysis to the

338 amorphous silica and calcite determined by mass balance calculations, the corrected values for the

339 quantitative analysis are $83.97 \mathrm{wt} \%$ augite, $9.86 \mathrm{wt} \%$ Na-phillipsite and $0.85 \mathrm{wt} \%$ hematite (Table

340 1). Thus, we assume that due to the resolution constraints of our Micro-CT equipment, the amounts

341 of Na-phillipsite and $\mathrm{CaCO}_{3}+$ amorphous $\mathrm{SiO}_{2}$ were slightly overestimated.

\section{3.2.2. Reacted diopside}

343 In the case of diopside subjected to dissolution in water at $\mathrm{pH} 7.5, \mathrm{XRD}$ and Rietveld analyses

344 (Figure 3a and S7) showed no major differences between unreacted and reacted samples, except for

345 the presence of $1.23 \mathrm{wt} \% \mathrm{Mg}$-Calcite (12 mol\% $\mathrm{Mg}$, Table S3), also confirmed by SEM-EDS 346 analyses (Figure 3b-c). As mentioned above, calcite precipitation could have been caused by the 347 presence of $\mathrm{CO}_{2}$ in the head space of the reactor. $\mu$-Raman analyses also confirmed the precipitation 
348 of this carbonate (Figure 3d). In addition, SEM-EDX and XRD analyses confirmed the presence of

349 hematite $(0.4 \mathrm{wt} \%)$. Rietveld analyses showed a very limited replacement of diopside by secondary

350 phases $(<2 \mathrm{wt} \%)$ and, in contrast with augite runs, no secondary crystalline silicates were detected.

351 However, SEM-EDS analyses showed the presence of $\mathrm{Ca}$ - and $\mathrm{Mg}$-free Si-rich precipitates in

352 dissolution pits and on the surface of diopside, which we interpret as silica gel (Figure 3e). Micro-

353 CT analyses (Figure S8) showed silica gel (2.7 wt\%) after 28 days of reaction, but only on the

354 surface of the reacted material. As in the case of the augite run, mass balance calculations were

355 performed to unravel the actual $\mathrm{SiO}_{2}$ content. This analysis shows that the value obtained by Micro-

356 CT analysis was overestimated, because our equipment could not differentiate between calcite and

357 amorphous silica (identified by XRD and SEM-EDS, respectively) as they show no detectable X-

358 ray attenuation contrast. Rietveld calculations were normalized to the $1.7 \mathrm{wt} \%$ amorphous $\mathrm{SiO}_{2}$

359 calculated by mass balance yielding 96.73 wt $\%$ diopside, and 1.23 wt $\%$ calcite (Table 1). In

360 contrast with augite runs, no pervasive fractures were identified by SEM or micro-CT analyses.

361 Apparently, while the formation of secondary crystalline silicate phases induces fracturing, this is

362 not the case for the precipitation of amorphous silica (see discussion section).

\section{$363 \quad 3.3 \quad$ Characterization of solids reacted in sodium bicarbonate solutions}

\section{3.3.1. Reacted augite}

365 XRD-Rietveld results (Figure 4a and S9) show that the reaction of augite in $\mathrm{NaHCO}_{3}$ solution led to

366 the formation of Na-phillipsite and calcite, as also occurred in the case of water. However, augite 367 replacement was substantially higher $(36.9 \mathrm{wt} \%)$ and secondary phases formation reached

368 maximum values as compared with the whole set of experimental results: 12.7 wt\% Na-phillipsite

369 (value very similar to water runs) and $22.3 \mathrm{wt} \%$ calcite. Importantly, the mass balance between $\mathrm{Si}$

370 in solution (Figure 1c) and reacted augite from Rietveld analysis showed an excess of Si that would 
371 be incorporated into an additional secondary Si-bearing phase, which was not detected by XRD or

372 SEM-EDS analyses. Based on the results of water runs (see above), we suggest that the missing Si

373 was incorporated into amorphous silica. Rietveld analyses were thus normalized to the $2.1 \mathrm{wt} \%$ of

374 newly formed amorphous silica calculated from mass balance (Table 1). SEM-EDS analyses

375 (Figure $4 \mathrm{~b}, \mathrm{c}$ ) showed massive pervasive fracturing of the starting augite crystals and confirmed the

376 presence of abundant Na-phillipsite and calcite precipitated within the fractures and on the surface

377 of the starting material. Well-developed rhombohedral calcite crystals $\sim 8 \mu \mathrm{m}$ in size with surface-

378 decorated iron-oxides were also identified. Calcite formation was confirmed by $\mu$-Raman analyses

379 (Figure 4d). Micro-CT analyses (Figure 4e) confirmed that the secondary phases precipitated within

380 the fractures cross-cutting the crystal and in the pores of the host augite crystal. Interestingly, Na-

381 phillipsite precipitated directly in contact with the fracture walls, filling the fractures inwards and

382 fully covering the surface of the walls. In contrast, calcite crystals appeared on the surface of the

383 pyroxene crystal and filling the cracks in contact with the Na-phillipsite (Figure S10), evidencing a

384 first precipitation of the zeolite and the subsequent formation of calcite. However, it cannot be ruled

385 out the possibility that, once the cracks appeared caused by the first precipitation of Na-phillipsite,

386 calcite started to precipitate contemporaneously to this zeolite. It should be noted that in this run the

387 amount of newly formed iron oxides reached the highest value of all experiments (2.01 wt $\%)$.

\subsubsection{Reacted diopside}

XRD-Rietveld analyses (Figures 5a and S11) of diopside showed a much higher level of replacement (12.6 wt\%) by newly formed phases in $\mathrm{NaHCO}_{3}$ solution than in water, but this value was significantly lower than that of augite reacted in bicarbonate solutions. Calcite was the most abundant secondary phase, showing a progressive increase up to $11.7 \mathrm{wt} \%$ over the whole span of the experiment, whereas iron oxides were, in all experiments, under $1 \mathrm{wt} \%$. Mass balance calculations showed that a fraction of precipitated $\mathrm{Si}$ was missing. As in the previous cases, this is 
interpreted as amorphous silica gel not detected by XRD. Quantitative Rietveld analysis results were normalized using the $1.27 \mathrm{wt} \%$ of amorphous $\mathrm{SiO}_{2}$ calculated from mass balance (Table 1).

397 Calcite precipitation was confirmed by $\mu$-Raman (Figure 5 b) showing the characteristic bands at $398286 \mathrm{~cm}^{-1}, 717 \mathrm{~cm}^{-1,}$ and $1085 \mathrm{~cm}^{-1}$, plus additional diopside bands, due to the relatively high beam 399 penetration depth. These inosilicate bands include: the symmetrical stretching vibration of bridging oxygen in $\mathrm{Si}-\mathrm{O}-\mathrm{Si}\left(\mathrm{Si}-\mathrm{O}_{\mathrm{br}}\right)$ at $663 \mathrm{~cm}^{-1}$, the symmetrical stretching vibration of non-bridging oxygen

401 in $\mathrm{Si}-\mathrm{O}\left(\mathrm{Si}-\mathrm{O}_{\mathrm{nbr}}\right)$ at $1012 \mathrm{~cm}^{-1}$ and, in the lower frequency region, four bands at $206 \mathrm{~cm}^{-1}, 316 \mathrm{~cm}^{-1}$, $402350 \mathrm{~cm}^{-1}$ and $385 \mathrm{~cm}^{-1}$ corresponding to the $\mathrm{Ca} / \mathrm{Mg}-\mathrm{O}$ vibrations (Buzatu and Buzgar, 2010). 403 Precipitation of calcite and iron oxides was also confirmed by SEM-EDS analyses (Figure 5c and 404 d). Rhombohedral calcite crystals were observed on the surface and within dissolution pits of the 405 diopside substrate. EDS analyses of calcite crystals showed a high Mg content (Figure 5c). From $406 \mathrm{XRD}$ analysis, the Mg content in calcite was determined to be $14.8 \mathrm{~mol} \%$. The highest Mg content 407 in calcite was observed in these runs, whereas in pure water a higher $\mathrm{Mg}$ content was observed in 408 diopside than in augite runs. Similar to the pure water systems, and in contrast with augite runs, 409 diopside crystals did not show massive pervasive fracturing as in the case of augite runs (inset in 410 Figure 5d). As a result, no secondary phases were detected in the interior of diopside crystals by 411 Micro-CT.

\section{$412 \quad 3.4$ Characterization of solids reacted in sodium carbonate solutions}

\section{3.4.1. Reacted augite}

414 After 28 days, the formation of $\mathrm{Mg}$-calcite $(12 \mathrm{~mol} \% \mathrm{Mg}$ ) was detected in augite samples along with hematite, whose content increased almost linearly with reaction time (Figures 6a and S12a).

416 Augite replacement in the $\mathrm{Na}_{2} \mathrm{CO}_{3}$ system was the lowest observed here (7.95 wt\%). $\mathrm{Mg}$-calcite 417 reached $6.9 \mathrm{wt} \%$, in good agreement with Micro-CT analyses (7.7 wt\%). Mg-calcite was principally 
418 present as rhombohedral crystals $\sim 16 \mu \mathrm{m}$ in size on the surface of the starting material and inside

419 surface cracks and dissolution pores (some extending deep into the pyroxene crystal), as shown by

420 SEM-EDS analyses (Figure 6b,c) and Micro-CT (Figure 6d). However, pervasive fracturing was

421 not observed within reacted augite crystals (Figure 6d). Furthermore, no Si-bearing secondary

422 phases were identified.

\section{3.4.2. Reacted diopside}

in $\mathrm{Na}_{2} \mathrm{CO}_{3}$ solution by low-magnesium calcite crystals ( $4 \mathrm{~mol} \% \mathrm{Mg}$, the lowest value of all runs).

SEM-EDS analysis of solids collected after 7 days of reaction (Figure 7a) showed the presence of a

calcium carbonate. Moreover, EDS analyses showed that the apparently amorphous Mg-silicate had

a $\mathrm{Mg} / \mathrm{Si}$ ratio of 0.72 , in good agreement with mass balance calculations yielding a $\mathrm{Mg} / \mathrm{Si}$ ratio of

0.63. The $\mathrm{Mg} / \mathrm{Si}$ ratio was calculated by mass balance as follows:

$$
\Delta_{M g}=m_{p y r}^{\prime}-\left(m_{\text {sol }}^{\prime}+m_{\text {prec }}^{\prime}\right)
$$

where $m_{\text {pyr }}^{\prime}$ is the mol $\%$ of $\mathrm{Mg}$ from the dissolved pyroxene obtained from the Rietveld analyses,

$m_{\text {sol }}^{\prime}$ is the Mg concentration in solution obtained by ICP-OES analyses and $m_{\text {prec }}^{\prime}$ is the mol \% of

Mg precipitated in the Mg-containing crystalline phases obtained by Rietveld analysis using a

Pseudo-Voigt $(n=0.5)$ for peak fitting and refinement. The difference in concentration obtained,

$\Delta_{M g}$, is interpreted here as the $\mathrm{Mg}$ contained in the $\mathrm{Mg}+\mathrm{Si}$-bearing amorphous phase.

Such values are in full agreement with the typical $\mathrm{Mg} / \mathrm{Si}$ ratios observed for magnesium silicate hydrate (MSH) gels (0.6-0.9) (Lothenbach et al., 2015; Bernard et al., 2017). After 28 days of reaction (Figure 7b), the MSH gel suffered a morphological transformation to a more condensed 
441 dissolution pits of diopside. Calcite crystals were associated with MSH on the surface and within

442 etch pits of the pyroxene (Figure 7b). Micro-CT (Figure 7c) analyses showed the distribution of

443 MSH along the dissolution areas and within the pores formed on the surface of diopside, but also in

444 several small cracks extending from the surface to the interior of the crystal (without cross-cutting

445 the whole crystal). Micro-CT based calculation of MSH + calcite content yielded 9.7 wt $\%$ of both

446 phases. If we subtract from this value the Rietveld value obtained for calcite, the MSH content

447 should be $7.45 \mathrm{wt} \%$. However, mass balance did not match these values, showing an excess of Si in

448 the system. Additional mass balance calculations were performed considering the $\mathrm{Si}$ and $\mathrm{Mg}$

449 content in solution, yielding a MSH content of $5 \mathrm{wt} \%$. Rietveld analyses were normalized to this

450 value (Table 1). Calcite could not be differentiated from MSH using micro-CT due to analytical

451 constraints (i.e., under our experimental conditions, the X-ray contrast of these two phases is very

452 similar, so our micro-CT analysis could not differentiate them).

MSH precipitation was confirmed by FTIR analyses (Figure 7d) showing the broad $\mathrm{v}-\mathrm{OH}$

stretching around $3400 \mathrm{~cm}^{-1}$ and the $\delta-\mathrm{OH}$ bending at $\sim 1615 \mathrm{~cm}^{-1}$ of water as well as a weak band at

$455 \sim 1240 \mathrm{~cm}^{-1}$ attributed to the $\mathrm{Q}_{3}$ stretching vibration of Si-O bonds, and a band at $\sim 1180 \mathrm{~cm}^{-1}$

456 corresponding to the $\mathrm{v}_{3}$ vibration of the $\mathrm{Si}-\mathrm{O}$ bond in fresh $\mathrm{MSH}$ gels, which is red-shifted from the

457 typical $v_{3} \mathrm{Si}-\mathrm{O}$ band of calcium silicate hydrate $(\mathrm{CSH})$ at $945 \mathrm{~cm}^{-1}$ (Ashraf and Olek, 2016;

458 Lothenbach et al., 2015). The presence of a carbonate phase was also confirmed by the $v_{3}$ band at

$459 \sim 1458 \mathrm{~cm}^{-1}$ (Ashraf and Olek, 2016; Gunasekaran et al., 2006). Calcite bands at 874 and $713 \mathrm{~cm}^{-1}$

460 were not detected due to the overlapping of the broadband of $\mathrm{v}_{\text {as }} \mathrm{Si}-\mathrm{O}-\mathrm{Si}$ vibration of diopside

461 (Omori, 1971; Mozgawa et al., 2004). To further corroborate the presence of MSH, $\mu$-Raman

462 analyses were performed (Figure 7e). The bands of diopside were detected, as well as the bands

463 corresponding to $\mathrm{O}-\mathrm{H}-\mathrm{O}$ vibrations at $219 \mathrm{~cm}^{-1}, \mathrm{O}-\mathrm{Si}-\mathrm{O}$ bending at $354 \mathrm{~cm}^{-1}$ and $\mathrm{Si}-\mathrm{O}-\mathrm{Si}$ 
464 symmetrical bending at 450 and $661 \mathrm{~cm}^{-1}$, corresponding to MSH (Lothenbach et al., 2015; Bernard 465 et al., 2017).

467 To better assess the carbonation extent of the different starting materials, values determined by

468 Rietveld refinement $\left(\xi_{\mathrm{n}}{ }^{\mathrm{RR}}\right)$ were plotted as a function of mass balance values $\left(\xi_{\mathrm{n}}{ }^{\mathrm{MB}}\right)$ (Eq. 3) (Figure

469 S14). Extents of carbonation determined by both methods are listed in Table 1. The slope and 470 correlation coefficient of the linear regression of the corresponding data $(N=3)$ for both analyses

471 were close to 1 , showing that the $\xi_{\mathrm{n}}$ values obtained by Rietveld analysis are in excellent agreement 472 with those obtained by mass balance analysis. These results support, on the one hand, that Rietveld 473 analysis is an accurate method for quantitative crystalline phase analysis, even in the case of 474 mineral phases present in very small amounts, and on the other hand, it gives extra reliability to our 475 experimental work.

\section{Discussion}

\section{4.1 Effect of pH and secondary phases precipitation during dissolution-carbonation}

478 Dissolution kinetics of inosilicate minerals are positively correlated with $\left[\mathrm{H}^{+}\right]$(e.g., Schott et al., 479 1981; McAdam et al., 2008; Schott et al., 2012). Therefore, the concentration of released divalent metals susceptible to contribute to the carbonation reaction is expected to be higher at close-toneutral than at highly alkaline pHs. However, carbonate precipitation is dependent on $\left[\mathrm{CO}_{3}{ }^{2-}\right]$, 482 which increases with $\mathrm{pH}$ (for a given value of DIC). Thus, a proper balance between these two key 483 parameters (i.e. $\left[\mathrm{CO}_{3}{ }^{2-}\right]$ and $\mathrm{pH}$ ), is of paramount importance to reach the highest possible 484 carbonation yield. In our case, this is achieved in sodium bicarbonate solution for both minerals studied here. If dissolution is considered the rate limiting step of the carbonation reaction, the 
take place in $\mathrm{Na}_{2} \mathrm{CO}_{3}$ solutions. This holds true for augite experiments (Table 1). However, a higher

488 level of diopside replacement was achieved in $\mathrm{Na}_{2} \mathrm{CO}_{3}$ than in water runs (Table 1), which points to 489 the existence of another kinetic limiting step.

Regarding free energy calculations (Eq. S2 and S3 and Table 2), it was observed that all systems had a negative free energy, enabling the dissolution of the pyroxenes. It is important to note that, systematically, $\Delta \mathrm{G}$ values of augite were lower (more negative) than those of diopside, resulting in higher expected dissolution rates and therefore, a higher augite replacement by secondary phases, as we observed experimentally in all runs.

Calculation of Saturation Index $\left(\mathrm{SI}_{\mathrm{cal}}\right)$ from measured concentrations in ICP-OES analyses using PHREEQc (Figure 8) shows that the highest calcite supersaturation is reached for augite in $\mathrm{NaHCO}_{3}$ runs. Due to the similar behavior of $\mathrm{SI}_{\text {cal }}$ for both pyroxenes, results for diopside $\mathrm{SI}$ modeling are not shown here. Low magnesium calcite ( 8-10 mol\%) presents a slightly lower solubility product than pure calcite (Morse and Bender, 1990). Thus, we can expect a slight increase of the calculated $\mathrm{SI}_{\mathrm{cal}}$ due to the $\mathrm{Mg}$ content, favoring $\mathrm{Mg}$-calcite precipitation. Furthermore, the precipitation of calcium carbonate causes a $\mathrm{pH}$ decrease (Figure 1) by proton release, which would foster further pyroxene dissolution. Thus, our model is in good agreement with our experimental results showing that in $\mathrm{NaHCO}_{3}$ runs calcite precipitation reached the highest yield as compared to 504 the other systems (24.6 wt\% in augite and $11.7 \mathrm{wt} \%$ in diopside). To explain why the $\mathrm{Mg}$ content in 505 precipitated calcite was maximum in diopside reacted in $\mathrm{NaHCO}_{3}$ runs, and minimum in diopside 506 reacted in $\mathrm{Na}_{2} \mathrm{CO}_{3}$ runs, we suggest that at neutral-to-moderately alkaline $\mathrm{pH}$ (bicarbonate and 507 water runs), the higher $\left[\mathrm{Ca}^{2+}\right] /\left[\mathrm{CO}_{3}{ }^{2-}\right]$ ratio (closer to unity) as compared to higher $\mathrm{pH}$ runs (with 508 higher $\left[\mathrm{CO}_{3}{ }^{2-}\right]$ ) in addition to the high $\mathrm{SI}_{\mathrm{cal}}$ could enable faster calcite growth favoring $\mathrm{Mg}$ 509 incorporation (Mavromatis et al., 2013). In addition, because $\mathrm{Mg}$ was incorporated in MSH, a phase which according to our SEM-EDX and micro-CT observations preceded the formation of $\mathrm{Mg}$ - 
511 calcite in diopside runs with $\mathrm{Na}_{2} \mathrm{CO}_{3}$ solution, there was a lower amount of $\mathrm{Mg}$ available to be 512 incorporated into calcite.

513 In agreement with Gadikota et al. (2014), who showed that the addition of $\mathrm{NaHCO}_{3}$ during 514 ex situ CCS fostered the carbonation of Ca-Mg silicates due to its buffer effect, we also observe 515 enhanced silicate dissolution-carbonation in $\mathrm{NaHCO}_{3}$ runs due to the relatively constant $\mathrm{pH}$ of the 516 reaction $(7.5<\mathrm{pH}<9)$. This relatively constant moderately alkaline $\mathrm{pH}$ enhances the dissolution of 517 the pyroxenes as compared to a strongly alkaline $\mathrm{pH}$. As a consequence, dissolution of these 518 silicates increases the amount of alkaline-earth metal ions fed to the solution susceptible to react 519 with $\mathrm{CO}_{3}{ }^{2-}$ ions. This is one factor that helps to explain why we obtain the highest levels of calcium 520 carbonate precipitation in bicarbonate runs. But it is not the only one (see below).

521 Regarding iron oxide precipitation, PHREEQc calculations (Figure S15) show that under the 522 whole $\mathrm{pH}$ range of our experiments, hematite was supersaturated. Therefore, precipitation of Fe523 oxides was expected right after $\mathrm{Fe}$ release following dissolution of the starting materials, in 524 agreement with Schwertmann (1991). As in the case of Mg-calcite, precipitation of Fe-oxides 525 should also favor the progress of the dissolution/carbonation according to Le Chatelier's principle.

526 Regarding secondary silicate phases, amorphous silica, MSH and Na-phillipsite precipitated 527 in our experiments despite the fact that the bulk solution was undersaturated with respect to the 528 latter. Our analysis of the solution chemistry evolution and SEM-EDS observations revealed that 529 amorphous silica was precipitated after a moderate alkalization in $\mathrm{NaHCO}_{3}$ and water runs. 530 Amorphous $\mathrm{SiO}_{2}$ was found within etch pits and as isolated precipitates on the surface of the 531 pyroxene crystals. The formation of etch pits and their filling by amorphous silica reveals that a 532 coupled dissolution-precipitation reaction at the mineral-fluid interface (i.e., interface-coupled 533 dissolution-precipitation, ICDP) was at work (Putnis, 2009; Ruiz-Agudo et al., 2012, 2016). 
534 According to previous works (i.e., Daval et al., 2009a; Ruiz-Agudo et al., 2012; Wild et al., 2019), 535 replacement processes taking place at the mineral-fluid interface result in strong compositional 536 gradients and important $\mathrm{pH}$ differences between the bulk solution and the mineral-fluid interface. 537 Such gradients enable the precipitation via an ICDP mechanism of secondary phases, 538 thermodynamically not possible in the bulk solution (Putnis, 2009), thus explaining the observed 539 formation of amorphous silica (as well as the other two secondary silicates, as discussed below) 540 despite the fact that this phase was unsaturated in the bulk solution.

541 Under the highly alkaline $\mathrm{pH}$ of the $\mathrm{Na}_{2} \mathrm{CO}_{3}$ runs, we detected no amorphous silica 542 precipitation; however, the highest Si concentration in solution was reached (Figure 1). This result 543 is consistent with the nearly exponential increase in silica solubility at $\mathrm{pH}>9$ (Fleming and Crerar, 544 1982; Monasterio-Guillot et al., 2019), not favoring its precipitation. On the other hand, because 545 pyroxene dissolution rates decrease with increasing $\mathrm{pH}$ (Schott et al., 2012), the Si release rate was 546 substantially lower in highly alkaline systems than in moderately alkaline ones.

547 Augite dissolution-carbonation at neutral-to-moderately alkaline $\mathrm{pH}$, led to the precipitation 548 of Na-phillipsite. Previous works have reported the precipitation of secondary Na-phillipsite 549 (commonly associated with amorphous Si-rich glass) during low- $T$ hydrothermal weathering of 550 basic and ultrabasic rocks rich in aluminum-augite in pelagic environments (Glaccum and Boström, 551 1976; Iyer et al., 2007). To model the evolution of the Saturation Index of Na-phillipsite (SI $\left.\mathrm{Sh}_{\text {pi }}\right)$ at 552 our experimental conditions, PHREEQc calculations were performed, showing values of $\mathrm{SI}_{\text {phi }}<0$ 553 (undersaturation) for all relevant $\mathrm{pH}$ values (i.e., $\mathrm{pH} \geq 7.5$ ) in our studied systems (Figure 8). The 554 latter indicates that it was not thermodynamically possible to precipitate this phase, contrary to our 555 experimental observations. As in the case of the precipitation of $\mathrm{SiO}_{2(\mathrm{am})}$ above discussed, if a 556 sufficiently high $\mathrm{Na}, \mathrm{Al}$ and $\mathrm{Si}$ release rate is achieved, a high supersaturation will be reached at the 557 mineral-fluid interface as to enable the heterogeneous precipitation of Na-phillipsite on the 
558 dissolving augite via an ICDP mechanism. In this respect, it is important to underline that a high

559 solute concentration can be achieved within the constrained volume of etch pits formed during 560 pyroxene dissolution (Plümper et al., 2012), and their pore surface will offer a large amounts of

561 sites for heterogeneous nucleation (Scherer, 1999; Putnis, 2009; Emmanuel and Ague, 2011; Schiro

562 et al., 2012). Altogether, these combined effects would favor the observed precipitation of Na563 phillipsite.

In our previous work (Monasterio-Guillot et al., 2019) we showed the formation of a secondary $\mathrm{Ca}+(\mathrm{Na} / \mathrm{K})$-bearing silicate (pectolite) during pseudowollastonite carbonation under equivalent conditions to those in this work. Other studies on pyroxenes and olivine carbonation 567 demonstrated the formation of secondary crystalline $\mathrm{Ca}$ and $\mathrm{Mg}$ silicates (King et al., 2010; 568 Sissmann et al., 2013), which fostered carbonation by the effect of side-reactions, as also shown here, but underlined that divalent metal incorporation into the secondary silicates was a handicap

570 for an effective CCS (Monasterio-Guillot et al., 2019). In our case, the observed incorporation of 571 small amounts of $\mathrm{Mg}$ in Na-phillipsite will also pose a handicap, yet very limited, for effective 572 carbonation of augite (Table S3).

The amount of $\mathrm{Na}^{+}$in $\mathrm{Na}_{2} \mathrm{CO}_{3}$ runs was double that in $\mathrm{NaHCO}_{3}$ runs, and orders of 574 magnitude higher than in water runs. However, no Na-aluminosilicates precipitated in the former 575 runs. This is likely due to the low dissolution rates of pyroxenes under strongly alkaline $\mathrm{pH}$, 576 preventing the build-up of sufficient supersaturation at the mineral-fluid interface as to enable Na577 phillipsite precipitation despite the higher Na content. The lack of secondary crystalline silicates in $578 \mathrm{Na}_{2} \mathrm{CO}_{3}$ solutions during augite carbonation led to the lowest level of replacement and calcite yield. 579 This emphasizes that the formation of secondary silicate phases is crucial to promote carbonation of 580 primary silicates (Monasterio-Guillot et al., 2019). 
582 the absence of $\mathrm{Al}$ in the elemental composition of this mineral. However, other crystalline 583 secondary $\mathrm{Ca}$ and/or Mg silicates could in theory be formed after diopside dissolution at neutral to 584 moderately alkaline $\mathrm{pH}$, as observed for instance after carbonation of olivine (King et al., 2010; 585 Sissman et al., 2013) and wollastonite (Daval et al. 2009a,b). In our closed systems, however, 586 diopside shows a lower dissolution rate than augite, as demonstrated by our ICP-OES analyses and 587 the \% replacement achieved after 28 days of reaction (Figure 1 and Table 1 ). Therefore, both the slow kinetics of Si release to the solution, and the limited amount of dissolution pits/pores formed on diopside as to favor heterogeneous nucleation of secondary crystalline silicates, seem to have contributed to the reduced yield of secondary phases observed here at moderately alkaline $\mathrm{pH}$. exemplified by the formation of MSH in the case of diopside runs. As indicated above, secondary Mg-bearing silicate phases could be interpreted as a handicap for effective $\mathrm{CO}_{2}$ capture. However, 594 Rietveld and mass balance analyses showed that carbonation yield of diopside during $\mathrm{Na}_{2} \mathrm{CO}_{3}$ experiments was double than that of water runs, in contrast to augite that reached similar carbonate yield in both runs (Table 1). The formation of MSH after dissolution of a Mg-Ca-pyroxene is not totally unexpected under our experimental conditions, because MSH is stable at moderately alkaline $\mathrm{pH}(\mathrm{p} \approx 7.5)$ (Bernard et al., 2017). The formation of MSH has been previously reported during olivine carbonation at $170{ }^{\circ} \mathrm{C}$ (Sissmann et al. 2013). However, the $\mathrm{Mg} / \mathrm{Si}$ ratio reported by Sissmann et al. (2013) was much higher $(\mathrm{Mg} / \mathrm{Si}=3.72)$ as compared to our experimental result $601(\mathrm{Mg} / \mathrm{Si} \sim 0.7)$. We suggest that this difference is due to the molar concentration of $\mathrm{Mg}$ in the 602 starting material (double in forsterite that in our pyroxenes), and to the higher dissolution rate of 603 olivine as compared with diopside (Schott et al., 2012). Following Sissmann et al. (2013) and 604 Lothenbach et al. (2015), PHREEQc calculations were performed using talc as a proxy to MSH, 
605 showing that such a Mg-rich silicate was supersaturated in the $\mathrm{Na}_{2} \mathrm{CO}_{3}$ solution and, therefore, 606 precipitation was expected. In this respect, we demonstrate that the precipitation of MSH during 607 diopside carbonation can foster its dissolution leading to enhanced Ca release. This effect helps to 608 explain why a higher amount of calcite was precipitated in this run as compared to the water run 609 (i.e., effect of side reactions). We suggest that the absence of MSH formation in augite during $610 \mathrm{Na}_{2} \mathrm{CO}_{3}$ runs is due to the higher dissolution rate of this phase as compared with diopside, resulting 611 in higher compositional gradients at the mineral interface that promoted the formation of Mg-calcite 612 as a Mg sink, instead of a Mg-rich silicate phase. Note that SEM-EDX analysis demonstrates that $613 \mathrm{MSH}$ formation precedes calcite formation on the surface of diopside, showing that the kinetics of 614 dissolution and carbonate precipitation in this system were sluggish.

To summarize, our results show that the formation of non-carbonate secondary precipitates

616 (i.e., Na-phillipsite, hematite, Magnesium Silicate Hydrates and amorphous silica), fostered the

617 dissolution and subsequent carbonation of the starting material. Altogether, our experimental results 618 demonstrate that the formation of secondary silicates (and oxides) played a key role in silicate 619 carbonation due to the importance of side reactions on enhanced dissolution of primary silicates and 620 on the subsequent effective carbonation (e.g., Frugier et al., 2008, and references therein).

\section{$621 \quad 4.2$ Effect of reaction-driven fracturing}

622 There is also another crucial effect associated with the precipitation of secondary phases that 623 strongly contributed to enhance augite and diopside carbonation: reaction-induced fracturing. In all 624 runs where Na-phillipsite precipitated, augite crystals showed massive pervasive fracturing (Figure 625 2d-f and Figure $4 \mathrm{~b}$ and e), whereas no such massive fracturing was observed in the rest of the 626 reacted crystals, with the exception of diopside run at high $\mathrm{pH}$ where some fracturing was observed 627 associated with MSH precipitation. As mentioned above, Na-phillipsite precipitation started in the 
628 (wedge-like) etch pits or pre-existing surface cracks/pores of the host material, and continued by

629 filling cracks generated by the crystallization of this phase. This reaction-driven fracturing is critical

630 for the advancement of the carbonation process, resulting in the highest replacement and carbonate

631 yields observed here. It is also expected to have an impact during GCS not just because $\mathrm{Ca}-\mathrm{Mg}-\mathrm{Al}$

632 pyroxenes are abundant in target rock-formation, but also because in such formations pore water is

633 typically saline, showing high $\mathrm{Na}$ concentrations and neutral-to-moderately alkaline pHs (Matter et

634 al., 2016), and volcanic glass and plagioclase dissolution may act as an additional Al source, which

635 may favor secondary Na-aluminosilicate formation likely resulting in fracturing.

Due to the difference in chemical potential between ions in solution and in a solid phase, a

637 pressure can be exerted by a solid crystallizing in a supersaturated solution, and such a 638 crystallization pressure can be transmitted to confining surfaces such as the walls of pores or cracks. 639 The crystallization pressure in pores large enough that curvature effects can be neglected is defined 640 by (Correns, 1949; Scherer 1999; Steiger, 2005),

$$
\Delta p=\frac{n R T}{V_{m}} \ln \frac{I A P}{k_{s p}}
$$

642 where $n$ is the number of ions forming the solid phase, $R$ is the gas constant, $T$ is the temperature, 643 IAP is the ion activity product, $k_{s p}$ is the solubility product (IAP/ $k_{s p}$ is the supersaturation, $\beta$ ) and $V_{m}$ 644 is the crystal molar volume. Eq. (6) shows that $\Delta p$ depends on supersaturation, which acts as a 645 driving force for crystallization pressure generation (Schiro et al., 2012). In general terms, the free 646 energy change $\Delta G_{r}$ associated with the formation of a new phase within a subcritical crack, such as 647 dissolution pits or pre-existing surface cracks in the pyroxenes, can lead to a significant $\Delta p$ if a 648 positive molar volume difference $\Delta V_{s}$ exists between the reactant and product phases, as predicted 649 by thermodynamics,

$$
\Delta p=-\frac{\Delta G_{r}}{\Delta V_{S}}
$$


651 Pressures of up to 300-400 MPa have been predicted using Eq. (7) for common reactions such as 652 olivine replacement by serpentine (Kelemen and Hirth, 2012) or alkali-silica reaction (ASR) in 653 cement (Ichikawa and Miura, 2007).

Failure of materials due to crystallization pressure generation within an elastic material 655 using an energy criterion will take place when the strain energy imposed by the growing crystals is 656 higher than the strain energy obtained during an uniaxial tensile strength test (Espinosa-Marzal et 657 al., 2011), i.e., when $\sigma_{c}>\sigma_{\mathrm{T}}$, where $\sigma_{c}$ is the critical stress and $\sigma_{\mathrm{T}}$ is the tensile strength. One way to 658 determine $\sigma_{c}$ involves the calculation of $\Delta p$ using Eq. (6). In our experiments, however, the 659 supersaturation at which Na-phillipsite crystallized is unknown, so we cannot calculate $\sigma_{c}$ using this 660 approach. However, we can estimate the stress required for the opening of a flaw or subcritical 661 crack (e.g., a notch- or wedge-like dissolution pit or pre-existing crack) following crystallization 662 pressure generation by a newly formed phase in such a confined space using fracture mechanics. 663 The critical stress can be calculated knowing the critical stress intensity (or fracture toughness) of a 664 particular solid, and for a particular flaw geometry. Here, we can consider the case of a semi665 circular flaw normal to the face exposed to the solution of a solid of semi-infinite length undergoing 666 internal pressurization (Jacobsen et al., 2015), as the geometry that can best represent surface etch 667 pits and preexisting surface cracks in pyroxene crystals (Figure 9a). In this case and for mode-I 668 fracturing, the stress intensity is (Tada et al., 1993),

$$
K_{I}=\frac{2}{\sqrt{\pi}}(1.211-0.186 \sqrt{\sin (\theta)}) \sigma \sqrt{c}
$$

670 where $\sigma$ is the internal stress within the flaw (or tensile stress pulling apart the surfaces of the flaw), $671 c$ is the radius of the semicircular flaw, and $\theta$ is the angle of the flaw with respect to the solid 672 surface. For a crack normal to the surface, the peak stress is at $\theta=\pi / 2$, and the critical stress to reach 673 the critical stress intensity $K_{I c}$ is (Jacobsen et al., 2015), 

$K_{I c}$ according to the Griffith's criterion for a brittle material under plane strain using the equation

677 (Griffith, 1920),

678

$$
K_{I c}=\sqrt{\frac{2 E \gamma}{1-v^{2}}}
$$

679 where $E$ is the Young modulus, $v$ is the Poison ratio, and $\gamma$ is the surface energy ( $2 \gamma$ is the energy 680 required to create new surfaces at the crack tip). In the case of augite, the reported values of $E$ and $v$ 681 are $143.76 \mathrm{GPa}$ (Aleksandrov et al., 1964) and 0.25 (Ji et al., 2009), respectively. Due to the 682 scarcity of (reliable) reported values for $\gamma$ of augite, we have used two different ones which help us 683 to establish a lower and upper bound of $K_{I c}$ for this pyroxene. The values are: $0.4 \mathrm{~J} \mathrm{~m}^{-2}$ reported for 684 augite by Miller (2010), and the theoretical value of $1.19 \mathrm{~J} \mathrm{~m}^{-2}$ for augite calculated using the 685 equation (Gilman, 1960),

$$
\gamma=\frac{E a^{2}}{d_{0} \pi^{2}}
$$

where $a$ is the atomic radius (or interatomic distance) of the atoms laying in the cleavage plane (here this value is taken as the average bond distance between oxygen and metal cations in M1 (i.e., $\mathrm{Al}, \mathrm{Fe}, \mathrm{Ti}$ ) and M2 (i.e., Ca, Mg) positions, equal to $2.28 \AA$; Cameron and Papike, 1981), and $d_{0}$ is the $d$-spacing of $\{h k l\}$ cleavage planes (i.e., weakest bond) in a particular crystal, which is $d_{110}=$ $6.42 \AA$ for the main $\{110\}$ cleavage planes of augite. The fact that the theoretical value of $\gamma$ for 692 augite calculated using Eq. (11) is nearly identical to the surface energy value of $1.2 \mathrm{~J} \mathrm{~m}^{-2}$ reported 693 for aegirine (Li et al., 2019) give us confidence about the reliability of our calculation method. Note 694 that augite and aegirine are isostructural and form a solid solution, so it is not unexpected for their 695 surface energy values to be very similar. Using the $\gamma$ values 0.4 and $1.19 \mathrm{~J} \mathrm{~m}^{-2}$, Eq. (10) yields the 
696 following $K_{I c}$ values: $0.35 \mathrm{MPa} \mathrm{m}^{1 / 2}$ and $0.61 \mathrm{MPa} \mathrm{m}^{1 / 2}$, respectively. For comparison, we have also 697 considered the $K_{I c}$ value of $1.28 \mathrm{MPa} \mathrm{m}^{1 / 2}$ reported for a diopside ceramic (Herman and Krzos, 698 2009). With the exception of the lowest value, the rest fall within the range of $K_{I c}$ values reported 699 for common silicate single crystals including olivine, quartz, feldspars, garnets and $\mathrm{Al}_{2} \mathrm{SiO}_{5}$ 700 polymorphs (Atkinson, 1984; Whitney et al., 2007). (c) calculated using Eq. (9), for the three $K_{I c}$ values indicated above. Using the measured value of $c$ $703=32 \pm 3 \mu \mathrm{m}$ for the case of augite subjected to crack opening following precipitation of $\mathrm{Na}$ 704 phillipsite in wedge-like each pits (measurements performed on SEM images, see Figure 9c-e), and 705 the three $K_{I c}$ values above indicated (ordered from lowest to highest value), Eq. (9) yields values of $\sigma_{\mathrm{c}}$ equal to $53 \pm 6,93 \pm 10$, and $196 \pm 20 \mathrm{MPa}$, respectively. The first value is rather low, likely because the low surface energy reported for augite by Miller (2010) using contact angle measurements is affected by surface reaction during measurement (i.e. $\mathrm{SiO}_{2 \mathrm{am}}$ formation). The $\sigma_{\mathrm{c}}$ value obtained for the case of the augite ceramic is likely higher than that expected for a single crystal, as monomineralic aggregates tend to have higher $K_{I c}$ values than single crystals (Van Noort et al., 2017). The $\sigma_{\mathrm{c}}$ value obtained using the calculated surface energy for augite seems to be the most realistic. Despite the uncertainties in the above reported values of critical stress $\sigma_{c}$, values in the order of $100 \mathrm{MPa}$ are apparently necessary for fracture opening in augite single crystals, meaning that crystallization of Na-phillipsite has to exert $\Delta p$ values higher than $\sim 100 \mathrm{MPa}$ within dissolution pits or preexisting cracks on the surface of augite crystals.

Our analysis yields $\sigma_{c}$ values of the same order of magnitude, but smaller than those 717 calculated for reaction-driven fracturing associated with olivine serpentinization ( 300 MPa) 718 (Kelemen and Hirth, 2012; Plumper et al., 2013). In any case our calculated $\sigma_{c}$ values are necessarily larger than the tensile strength of (unconstrained) augite crystals, otherwise no reaction- 
driven fracturing would have been observed. Note that while the theoretical maximum tensile

721 strength for a crystal is $\sim E / 10$ (i.e., $\sim 15 \mathrm{GPa}$ for augite), the actual value is typically much lower

722 because of the presence of flaws (Idrissi et al., 2016), explaining why fracturing of augite is

723 observed under the calculated $\sigma_{c}$ values. To the best of our knowledge, the tensile strength of augite

724 single crystals has not been reported. However, a spalling fracture stress of $58 \mathrm{MPa}$ (equivalent to

725 tensile strength failure under very high strain rates) has been reported for an augite-rich (65\%)

726 peridotite (He et al., 1996). This stress can be considered as a lower bound for the stresses actually

727 resulting in fracturing of our augite single crystals upon Na-phillipsite crystallization.

Using Eq. (6), and the most reliable critical stress of $93 \mathrm{MPa}$ obtained here using fracture

mechanics, a supersaturation $\beta=2.69$ for Na-phillipsite $\left(\mathrm{NaAlSi}_{3} \mathrm{O}_{8} \cdot 3 \mathrm{H}_{2} \mathrm{O}, n=4\right.$, and $V_{m}=149.69$

$730 \mathrm{~cm}^{3} \mathrm{~mol}^{-1}$; data from Blanc et al., 2015) crystallization within augite is obtained (at $423 \mathrm{~K}$ ). Such a relatively high, yet reasonable $\beta$ value, corresponding to a $\mathrm{SI}_{\mathrm{phi}}$ of 0.42 , underlines that the supersaturation that can be reached at the mineral-solution interface during an ICDP process can be significantly high, even when the bulk system is undersaturated to a particular phase, as shown here by our PHREEQc modeling. If we consider a lower bound for the crystallization pressure equal to the dynamic tensile strength of augite-rich peridotite (58 MPa), then a $\beta$ value of 1.85 is calculated from Eq. (6), which also demonstrates that for fracture generation a significant but reasonable supersaturation has to be generated at the mineral-solution interface in dissolution pits. Still, there is a potential problem regarding the calculated crystallization pressure: for a crystal to transmit such a pressure to a confining surface, a fluid (few nm thick) has to exist between the crystal and the

740 confining surface, so that a disjoining pressure must exist that is at least equal to such a 741 crystallization pressure (Scherer, 2004). It is not clear whether a fluid would not be squeezed out 742 leading to direct contact between the crystals and the confining wall under a crystallization pressure of several tens or even hundred $\mathrm{MPa}$, so that no crystallization pressure can be transmitted. In this 
respect, Zheng et al. (2018) report that confining pressures higher than $30 \mathrm{MPa}$ prevented reaction-

745 induced fracturing during the hydration of $\mathrm{MgO}$ (which can in theory generate crystallization

746 pressure values of over $1 \mathrm{GPa}$ ). This was interpreted assuming that the liquid was squeezed out of

747 the reaction interface, and no disjoining pressure could be developed. Yet, this could be also due to

748 relaxation of crystallization pressure through viscous creep due to the fact that brucite is a

749 mechanically weak mineral. Disjoining pressures higher than $75 \mathrm{MPa}$ have been predicted by

750 Renard and Ortoleva (1997) to explain pressure solution at crustal depth of over $5 \mathrm{~km}$. It can thus be

751 argued that in our experiments effective disjoining pressures of the same order of magnitude of

752 predicted crystallization pressures can be attained. Alternatively, it could be argued that a

753 significantly lower crystallization pressure (few tens of MPa) could easily develop in our system,

754 and generate stress on the surrounding confining fluid within an etch pit as to trigger a phenomenon

755 of stress corrosion (Ciccotti, 2009), enabling the opening of a crack at the tip of wedge-like

756 dissolution pits or pre-existing cracks at crystallization pressures significantly lower than those

757 calculated here.

758 Once crack opening has taken place, further propagation of the cracks would take place by

759 additional crystallization of Na-phillipsite within such a constrained space, provided that such a

760 phase crystallizes at a sufficiently high supersaturation. The fact that our SEM and micro-CT

761 images show augite crystals cross-cut by fractures completely filled by Na-phillipsite, leading to a

762 very wide fractures (widths of more than several tens of $\mu \mathrm{m}$ ) is direct evidence that crystallization

763 pressure was exerted, enabling fracture propagation. This should be facilitated by the fact that once

764 fractures have been opened, the effective bulk modulus will be a fraction of the modulus of the 765 intact crystal.

766 A similar approach could be used to calculate the effective pressure and supersaturation at 767 the onset of MSH crystallization within diopside crystals, leading to its fracturing. In this case, 
however, the level of reaction-driven fracturing was more limited (i.e., no large, cross-cutting

769 fractures were observed), but in any case, reaction-driven stresses larger than the tensile strength of

770 diopside had to be generated to produce the observed fractures filled by MSH. Because MSH is an

771

772

773

774

775

776

777

778

779

780

781

782

783

784

785

786

787

788

789

790

791

amorphous gel-like material, and its solubility should be relatively high, a sufficient high supersaturation as to create enough crystallization pressures to fracture diopside is unlikely. However, it could be argued that fracturing takes place not by crystallization pressure generation, but most likely via an expansion mechanism similar to that observed for ASR resulting in cement fracturing (Rajabipour et al., 2015). Amorphous silica gel hydration can reportedly result in pressures of over 20-30 MPa (Reinhardt and Mielich, 2012) and, in theory, pressures of up to 400 MPa could be generated during alkali-silica reaction (ASR, Ichikawa and Miura, 2007). If a stress corrosion effect takes place concurrently, fracture opening and propagation would likely take place even at the relatively low gel hydration pressures above indicated.

Large amounts of calcite were identified within fractures generated in the $\mathrm{NaHCO}_{3}$ system during augite carbonation. It could therefore be argued that calcite crystallization also contributed to fracture generation, as reported for newly formed carbonates during primary silicate mineral carbonation (Kelemen et al., 2011; Kelemen and Hirth, 2012). However, due to the no contact between calcite and the fracture walls cross-cutting augite crystals observed in the Micro-CT analyses (Figure 4e), as well as SEM-EDS (Figure 4b) results showing that Na-phillipsite is directly in contact with augite walls, whereas calcite precipitated on the surface of the pyroxene and in contact with the newly formed zeolite, we conclude that calcite did not generate the cracks but likely contributed to their widening.

The fact that no pervasive fractures were observed in any other experiments despite the precipitation of calcite and amorphous silica, demonstrates that the supersaturation at the onset of crystallization of these phases within preexisting cracks and newly-formed dissolution (wedge-like) 
etch pits was not high enough to generate an effective pressure higher than the tensile strength of

793 the pyroxene crystals. Similarly, possible expansion due to amorphous silica gel by a process

794 similar to ASR, was not sufficient to create any fracturing.

In addition to the above-mentioned mechanisms, other reaction-driven fracturing mechanism

have been proposed. Jamtveit et al. (2000) explored the idea that fracture generation was caused by

tensile stress generation due to solid volume decrease during mineral dissolution. However, this

798 kind of process is ruled out here based on the absence of fracture generation during augite and

799 diopside reactions in runs were no Na-phillipsite or MSH precipitated, but still dissolution occurred

800 and a certain degree of replacement was obtained. Zhu et al. (2016) suggested that volume

expansion of carbonated areas in porous granular aggregates of olivine, could induce tensile stresses

and associated fracturing in non-reacted areas resulting in a crack pattern very similar to drying-

cracks. However, such an effect is not observed in any of our experiments. Note that Zhu et al.

(2016) experiments showed intergranular cracks whereas our experiments resulted in intragranular cracks.

Typically, precipitation of newly formed phases during replacement reactions such as

silicate carbonation can passivate the reaction by decreasing the reactive surface area in turn reducing porosity and permeability (e.g. Emmanuel and Ague, 2011; Di Lorenzo and Prieto, 2017).

Dissolution processes without crack development can create porosity and increase the reactive surface area (Lafay et al., 2018), especially if wormholing (channelized dissolution) takes place (Ott and Oedai, 2015). However, our results show that in the case of the studied pyroxenes, dissolution

812 without pervasive cracking does not enable a significant advance of the replacement reaction.

813 Conversely, our results demonstrate that reaction-driven fracturing due to crystallization pressure 814 generation (Scherer, 1999; Schiro et al., 2012) likley associated with stress corrosion, or amorphous MSH gel expansion, is critical for the advance of silicate dissolution and carbonate precipitation, 
because it increases the permeability of the substrate and the available reactive surface area

817 (Kelemen et al., 2011; Kelemen and Hirth, 2012).

819 4.3. Origin of the differences in carbonation behavior of diopside and augite

820 Despite their very similar chemical composition and structure, augite and diopside display a very 821 different dissolution and carbonation behavior. In particular, a systematically higher extent of augite

822 dissolution and carbonation was observed (Table 1). Previous studies showed that augite has a 823 higher dissolution rate than diopside over a whole range of pHs (McAdam et al., 2008; Schott et al., 824 2012). Furthermore, previous works on dissolution of iron-bearing pyroxenes (Siever and 825 Woodford, 1979; Hoch et al., 1996) showed that they present a higher dissolution rate than non826 iron-bearing pyroxenes due to the formation of highly insoluble Fe-oxides and hydroxides that shift 827 the equilibrium to the product side. In particular, Hoch et al. (1996) showed that the higher 828 dissolution rate of augite as compared with diopside was related to the oxidation of iron present in 829 higher amounts in the former clinopyroxene. Our augite crystals include 2.3 mol\% Fe, while 830 diopside includes $1.7 \mathrm{~mol} \% \mathrm{Fe}$. The higher Fe content in augite likely contributed to its faster 831 dissolution according to the effect indicated above. Furthermore, we suggest that the presence of $\mathrm{Na}$ 832 and $\mathrm{Al}$ in augite contributed both to a faster release of divalent metals and silicate species to the 833 solution and to the formation of secondary Na-aluminosilicates, thereby increasing the overall 834 dissolution rate of this pyroxene (Berger et al., 1994). Altogether, our results suggest that the 835 presence of $\mathrm{Al}$ and the faster and ultimately higher release of $\mathrm{Si}, \mathrm{Fe}$, alkali, and alkaline-earth 836 metals to the solution in the case of augite fostered, on the one hand, the shift of the dissolution837 carbonation reaction to the products side and, on the other hand, the precipitation of secondary 838 phases in etch pits and surface pores/cracks at a sufficiently high supersaturation as to generate 
crystallization pressure sufficient to result in massive fracturing and a significant increase in

840 reactive surface area. These two effects created a strong positive dissolution-precipitation feedback-

841 loop in the case of augite, which was not so strong in the case of diopside, thereby explaining the

842 observed higher conversion and carbonate yield.

\section{5. Conclusions}

844 The implications of the results obtained during this work are manifold. A critical aspect highlighted 845 by our results is the important role of secondary phase precipitation on the advancement of the 846 reactions, not contemplated in the conversion of pyroxenes into carbonates. The formation of 847 secondary iron oxides and crystalline and amorphous secondary silicates provides a free energy

848 contribution to the system, allowing the progress of the carbonation reaction. The high amounts of 849 secondary phases observed in augite experiments with DIC in solution enhanced the progress of the 850 reaction as compared with pure water, while in diopside systems, the small amount of secondary

851 phases did not enhance this progress. These results show that the presence of DIC in the system is 852 crucial for the progress of the reaction, acting as a generator of secondary phases that contribute to 853 shift the reaction towards the product side, but the effectiveness of this process is strongly 854 dependent of the specific crystal chemistry of the pyroxenes.

Also, we show the formation of secondary phases filling dissolution pits and fractures whose precipitation was, in theory, thermodynamically not possible in our systems. This demonstrates that 857 these latter transformations could only be achieved by an interface-coupled dissolution-precipitation 858 mechanism, where supersaturation with respect to specific phases could be reached at the interface 859 between the mineral and the solution (Putnis 2009, Putnis 2014, Ruiz-Agudo et al. 2012, 2016). 
moderately-alkaline than in strongly alkaline $\mathrm{pH}$ systems. This effect has a direct impact on the

863 formation of secondary phases, fostering their precipitation in large amounts in the former case and

864 hampering the progress of the reaction in the latter.

Our experimental results also demonstrate that the in-pore crystallization of secondary crystalline phases (Na-phillipsite) and, to a lesser extent amorphous ones (MSH), is responsible of

867 the fracture generation and propagation during dissolution-carbonation processes. We show that the 868 reaction-driven fracturing derives from crystallization pressure, and in the case of MSH, most likely

869 due to gel expansion. In both cases stress corrosion should also contribute to the observed crack 870 development. Reaction-driven fracturing is shown to be crucial for the progress of the 871 dissolution/carbonation reaction, because it exposes fresh reactive mineral surface and enables fluid 872 transport within pyroxene crystals. The calculated critical stress for pyroxene (augite) fracture is $873 \sim 100 \mathrm{MPa}$. This value implies that fracturing will likely occur during clinopyroxene carbonation in 874 real GCS scenarios, down to a depth of $\sim 4 \mathrm{~km}$, when the lithostatic pressure equals such pressure. 875 Note that if the lithostatic pressure (plus pore fluid pressure) were higher than the stress associated 876 to secondary silicate formation, then no fracturing would take place (Malvoisin et al., 2017). Our 877 results therefore show that reaction-driven fracturing of pyroxenes would be a major contributor to $878 \mathrm{CO}_{2}$ mineral capture during standard low-to-medium depth GCS.

879 Finally, we experimentally demonstrate that the amount of $\mathrm{Al}, \mathrm{Fe}$ (and $\mathrm{Na}$ ) ions in the 880 pyroxenes has a strong effect during dissolution-carbonation processes, explaining why augite, 881 which includes a higher $\mathrm{Fe}, \mathrm{Na}$, and $\mathrm{Al}$ content than diopside, shows the highest dissolution rate and 882 the highest conversion and carbonate yield.

Altogether, these results provide relevant information to be considered for the enhancement 884 of the GCS using silicate carbonation strategies. In particular, this study sheds light on the 
importance of the silicate mineral composition of rock formations during in situ CCS, showing the

886 importance of secondary (alumino)silicate formation on reaction-driven fracture development,

887 providing flow channels and fresh reactive surface areas to improve the carbonation reaction.

\section{ACKNOWLEDGMENTS}

890 European Commission (ERDF funds), the Junta de Andalucía (research group RNM-179), and the

891 University of Granada (Unidad Científica de Excelencia UCE-PP2016-05). LMG acknowledges

892 funding by the Spanish Government FPI (Grant BES-2016-078468). We thank Prof. George W.

893 Scherer for his comments and suggestions regarding reaction-driven stress generation. We also

894 thank the personnel of the Centro de Instrumentación Científica (CIC; University of Granada) and

895 the personnel of the ISTerre for assistance with ICP-OES, Micro-CT, and SEM analyses. The use of 896 the analytical chemistry platform of ISTerre is acknowledged.

\section{References}

Aleksandrov, K. S.; Ryzhova, T. V. and Ryzhova, B. P. (1964). The elastic properties of pyroxenes. Soviet Phys. Cryst. 8, 589-591.

Ashraf W. and Olek J. (2016) Carbonation behavior of hydraulic and non-hydraulic calcium silicates: potential of utilizing low-lime calcium silicates in cement-based materials. J. Mater. Sci. 51.

Atkinson, B. K. (1984). Subcritical crack growth in geological materials. J. Geophys. Res. Solid Earth, 89, 4077-4114.

Banfield J. F., Ferruzzi G. G., Casey W. H. and Westrich H. R. (1995) HRTEM study comparing naturally and experimentally weathered pyroxenoids. Geochim. Cosmochim. Acta 59, 19-31. implications for long-term alteration. Geochim. Cosmochim. Acta 58, 4875-4886. 
908

909

910

911

912

913

914

915

916

917

918

919

920

921

922

923

924

925

926

927

928

929

930

Bernard E., Lothenbach B., Le Goff F., Pochard I. and Dauzères A. (2017) Effect of magnesium on calcium silicate hydrate (CSH). Cem. Concr. Res. 97, 61-72.

Berner R. A. and Caldeira K. (1997) The need for mass balance and feedback in the geochemical carbon cycle. Geology 25, 955-956.

Berner R. A., Sjöberg E. L., Velbel M. A. and Krom M. D. (1980) Dissolution of pyroxenes and amphiboles during weathering. Science 207, 1205-1206.

Berner, R.A., Lasaga, A.C. and Garrels, R. M. (1985). The carbonate-silicate geochemical cycle and its effect on atmospheric carbon dioxide over the past 100 million years. Am. J. Sci. 283, 641-683.

Blanc P., Vieillard P., Gailhanou H., Gaboreau S., Gaucher E., Fialips C. I., Madé B. and Giffaut E. (2015) A generalized model for predicting the thermodynamic properties of clay minerals. Am. J. Sci. 315, 734-780.

Bersani D., Lottici P. P. and Montenero A. (1999) Micro-Raman investigation of iron oxide films and powders produced by sol-gel syntheses. J. Raman Spectrosc. 30, 355-360.

Bodor, M., Santos, R. M., Kriskova, L., Elsen, J., Vlad, M. and Van Gerven, T. (2013). Susceptibility of mineral phases of steel slags towards carbonation: mineralogical, morphological and chemical assessment. Eur. J. Mineral. 25, 533-549.

Buzatu A. and Buzgar N. (2010) The Raman study of single-chain silicates. Analele Stiint. Univ. AI Cuza din Iasi. Sect. 2, Geol. 56, 107.

Cameron, M. and Papike, J.J. (1981) Structural and chemical variations in pyroxenes. Am. Miner. 66, 1-50.

Casey W. H., Westrich H. R. and Arnold G. W. (1988) Surface chemistry of labradorite feldspar reacted with aqueous solutions at $\mathrm{pH}=2,3$, and 12. Geochim. Cosmochim. Acta 52, 2795-2807.

Casey, W. H., Westrich, H. R., Banfield, J. F., Ferruzzi, G., \& Arnold, G. W. (1993). Leaching and reconstruction at the surfaces of dissolving chain-silicate minerals. Nature 366, 253-256. 
931

932

933

934

935

936

937

938

939

940

941

942

943

944

945

946

947

948

949

950

951

952

953

954

Chamritski I. and Burns G. (2005) Infrared-and Raman-active phonons of magnetite, maghemite, and hematite: a computer simulation and spectroscopic study. J. Phys. Chem. B 109, 4965-4968.

Ciccotti, M. (2009). Stress-corrosion mechanisms in silicate glasses. J. Phys. D 42, 214006.

Correns, C. W. (1949) Growth and dissolution of crystals under linear pressure. Disc. Farad. Soc. 5, 267271.

Daval D., Hellmann R., Saldi G. D., Wirth R. and Knauss K. G. (2014) Linking nm-scale measurements of the anisotropy of silicate surface reactivity to macroscopic dissolution rate laws: New insights based on diopside. Geochim. Cosmochim. Acta 107, 121-134.

Daval D., Martinez I., Corvisier J., Findling N., Goffe B. and Guyot F. (2009a) Carbonation of Ca-bearing silicates, the case of wollastonite: Experimental investigations and kinetic modeling. Chem. Geol. 265, $63-78$.

Daval D, Martinez I., Guigner J. M., Hellmann R., Corvisier J., Findling N., Dominici C., Goffe B. and Guyot F. (2009b) Mechanism of wollastonite carbonation deduced from micro- to nanometer length scale observations. Am. Mineral. 94, 1707-1726.

Davidson, P. M., \& Lindsley, D. H. (1985). Thermodynamic analysis of quadrilateral pyroxenes. Contrib. Mineral. Petrol. 91, 390-404.

Deer, W. A., Howie, R. A., \& Zussman, J. (1966). An Introduction to the Rock Forming Minerals. The Mineralogical Society, London.

Di Lorenzo F. and Prieto M. (2017) Dissolution-Recrystallization of (Mg,Fe)CO 3 during Hydrothermal Cycles: $\mathrm{Fe}^{\mathrm{II}} / \mathrm{Fe}^{\mathrm{III}}$ Conundrums in the Carbonation of Ferromagnesian Minerals. Cryst. Growth Des. 17, 4170-4182.

Di Lorenzo F., Ruiz-Agudo C., Ibañez-Velasco A., Gil-San Millán R., Navarro J., Ruiz-Agudo E. and Rodriguez-Navarro C. (2018) The carbonation of wollastonite: A model reaction to test natural and biomimetic catalysts for enhanced $\mathrm{CO}_{2}$ sequestration. Minerals $\mathbf{8}, 209$. 
955

956

957

958

959

960

961

962

963

964

965

966

967

968

969

970

971

972

973

974

975

976

977

Dixit S. and Carroll S. A. (2007) Effect of solution saturation state and temperature on diopside dissolution. Geochem. Trans. 8, 1-14.

Driscoll, F. G. (1986). Groundwater and Wells. Reynolds Guyar Design Publisher Austin, Minnesota.

Emmanuel, S., \& Ague, J. J. (2011). Impact of nano-size weathering products on the dissolution rates of primary minerals. Chem. Geol. 282, 11-18.

Espinosa-Marzal, R. M., Hamilton, A., McNall, M., Whitaker, K., \& Scherer, G. W. (2011). The chemomechanics of crystallization during rewetting of limestone impregnated with sodium sulfate. $J$. Mater. Res. 26, 1472-1481.

Fleming B. A. and Crerar D. A. (1982) Silicic acid ionization and calculation of silica solubility at elevated temperature and $\mathrm{pH}$ application to geothermal fluid processing and reinjection. Geothermics 11, 15-29.

Frugier, P., Gin, S., Minet, Y., Chave, T., Bonin, B., Godon, N., Lartigue, J.E., Jollivet, P., Ayral, A., De Windt, L., Santarini, G., 2008. SON68 nuclear glass dissolution kinetics: Current state of knowledge and basis of the new GRAAL model. J. Nuclear Mater. 380, 8-21.

Gadikota G., Matter J., Kelemen, P. and Park A. (2014) Chemical and morphological changes during olivine carbonation for $\mathrm{CO}_{2}$ storage in the presence of $\mathrm{NaCl}$ and $\mathrm{NaHCO}_{3}$. Phys. Chem. Chem. Phys 16, 4679.

Gilman, J. J. (1960), Direct measurement of the surface energies of crystals. J. Appl. Phys. 31, 2208-2218.

Glaccum R. and Boström K. (1976) (Na, K)-phillipsite: Its stability conditions and geochemical role in the deep sea. Mar. Geol. 21, 47-58.

Goldsmith J. R., Graf D. L., Chodos A. A., Joensuu O. I. and McVicker L. D. (1958) Relation between lattice constants and composition of Ca-Mg carbonates. Am. Mineral. 43, 84-101.

Griffith, A. A. (1921). VI. The phenomena of rupture and flow in solids. Phil. Trans. Royal Soc. London A, 221, 163-198.

Gunasekaran S., Anbalagan G. and Pandi S. (2006) Raman and infrared spectra of carbonates of calcite 
structure. J. Raman Spectrosc. 37, 892-899.

979 He, H., Jin, X., Jing, F., \& Ahrens, T. J. (1996). Characteristic of dynamic tensile fracture in augite980 peridotite. AIP Conf. Proc., 370, 593-596.

981 Hellmann R., Daval D. and Wirth R. (2013) Formation of amorphous silica surface layers by dissolution982 reprecipitaton during chemical weathering: Implications for $\mathrm{CO}_{2}$ uptake. Procedia Earth Planet. Sci. 7, $983 \quad 346-349$.

984 Hellmann R., Wirth R., Daval D., Barnes J. P., Penisson J. M., Tisserand D., Epicier T., Florin B. and Hervig 985 R. L. (2012) Unifying natural and laboratory chemical weathering with interfacial dissolution986

Herman, D., \& Krzos, J. (2009). Influence of vitrified bond structure on radial wear of cBN grinding wheels. reprecipitation: A study based on the nanometer-scale chemistry of fluid-silicate interfaces. Chem. Geol. 294-295, 203-216.

990

991

Hoch A. R., Reddy M. M. and Drever J. I. (1996) The effect of iron content and dissolved $\mathrm{O}_{2}$ on dissolution rates of clinopyroxene at pH 5.8 and 25 C: preliminary results. Chem. Geol. 132, 151-156.

Ichikawa, T., \& Miura, M. (2007). Modified model of alkali-silica reaction. Cem. Concr. Res. 37, 1291993 1297.

994

Idrissi, H., Bollinger, C., Boioli, F., Schryvers, D., \& Cordier, P. (2016). Low-temperature plasticity of 995 olivine revisited with in situ TEM nanomechanical testing. Sci. Advances 2, e1501671.

996

IPCC (2014). Climate change 2014: synthesis report. Contribution of Working Groups I, II and III to the 997 fifth assessment report of the Intergovernmental Panel on Climate Change (p. 151). IPCC.

998 Iyer S. D., Sudhakar M. and Das P. (2007) Composition and genesis of zeolitic claystones from the Central 999 Indian Ocean Basin. Acta Geol. Sin. Ed. 81, 756-770.

1000 Jacobsen, S., Scherer, G. W., \& Schulson, E. M. (2015). Concrete-ice abrasion mechanics. Cem. Concr. Res. 
1002

1003

1004

1005

1006

1007

1008

1009

1010

1011

1012

1013

1014

1015

1016

1017

1018

1019

1020

1021

1022

1023

Jamtveit, B., Austrheim, H., \& Malthe-Sørenssen, A. (2000). Accelerated hydration of the Earth's deep crust induced by stress perturbations. Nature, 408, 75-78.

Ji, S., Wang, Q., \& Salisbury, M. H. (2009). Composition and tectonic evolution of the Chinese continental crust constrained by Poisson's ratio. Tectonophysics, 463, 15-30.

Kelemen, P. B., Matter, J., Streit, E. E., Rudge, J. F., Curry, W. B., \& Blusztajn, J. (2011). Rates and mechanisms of mineral carbonation in peridotite: natural processes and recipes for enhanced, in situ CO2 capture and storage. Ann. Rev. Earth Planet. Sci. 39, 545-576.

Kelemen, P. B., \& Hirth, G. (2012). Reaction-driven cracking during retrograde metamorphism: Olivine hydration and carbonation. Earth Planet. Sci. Lett. 345, 81-89.

King H. E., Plümper O. and Putnis A. (2010) Effect of secondary phase formation on the carbonation of olivine. Environ. Sci. Technol. 44, 6503-6509.

Knauss K. G., Nguyen S. N. and Weed H. C. (1993) Diopside dissolution kinetics as a function of pH, $\mathrm{CO}_{2}$, temperature, and time. Geochim. Cosmochim. Acta 57, 285-294.

Lackner K. S., Wendt C. H., Butt D. P., Joyce E. L. and Sharp D. H. (1995) Carbon dioxide disposal in carbonate minerals. Energy 20, 1153-1170.

Lafay, R., Montes-Hernandez, G., Renard, F., \& Vonlanthen, P. (2018). Intracrystalline reaction-induced cracking in olivine evidenced by hydration and carbonation experiments. Minerals $\mathbf{8}, 412$.

Li, M., Liu, J., Gao, X., Hu, Y., Tong, X., Zhao, F. and Yuan, Q. (2019). Surface properties and floatability comparison of aegirite and specularite by density functional theory study and experiment. Minerals $\mathbf{9}$, 782.

Lothenbach B., Nied D., L’Hôpital E., Achiedo G. and Dauzères A. (2015) Magnesium and calcium silicate hydrates. Cem. Concr. Res. 77, 60-68. 
1024

1025

1026

1027

1028

1029

1030

1031

1032

1033

1034

1035

1036

1037

1038

1039

1040

1041

1042

1043

1044

1045

1046

1047

Loucks, R. R. (1996). A precise olivine-augite Mg-Fe-exchange geothermometer. Contrib. Mineral. Petrol. 125, 140-150.

Malvoisin, B., Brantut, N., \& Kaczmarek, M. A. (2017). Control of serpentinisation rate by reaction-induced cracking. Earth Planet. Sci. Lett. 476, 143-152.

Matter, J. M., \& Kelemen, P. B. (2009). Permanent storage of carbon dioxide in geological reservoirs by mineral carbonation. Nat. Geosci. 2, 837-841.

Matter, J. M., Stute, M., Snæbjörnsdottir, S. Ó., Oelkers, E. H., Gislason, S. R., Aradottir, E. S., Sigfusson, B., Gunnarsson, I., Sigurdardottir, H., Gunnlaugsson, E., Axelsson, G., Alfredsson, H.A., WolffBoenisch, D., Mesfin, K., Fernandez de la Reguera Taya, D., Hall, J., Dideriksen, K., Broecker, W.S. (2016) Rapid carbon mineralization for permanent disposal of anthropogenic carbon dioxide emissions. Science, 352, 1312-1314.

Mavromatis V., Gautier Q., Bosc O. and Schott J. (2013) Kinetics of Mg partition and Mg stable isotope fractionation during its incorporation in calcite. Geochim. Cosmochim. Acta 114, 188-203.

McAdam A. C., Zolotov M. Y., Sharp T. G. and Leshin L. A. (2008) Preferential low-pH dissolution of pyroxene in plagioclase-pyroxene mixtures: Implications for martian surface materials. Icarus 196, 9096.

McGrail B. P., Schaef H. T., Ho A. M., Chien Y. J., Dooley J. J. and Davidson C. L. (2006) Potential for carbon dioxide sequestration in flood basalts. J. Geophys. Res. Solid Earth 111, 1-13.

Miller, C.M. (2010) Adhesion and the Surface Energy Components of Natural Minerals and Aggregates. Ms Thesis, Texas A\&M University.

Monasterio-Guillot L., Di Lorenzo F., Ruiz-Agudo E. and Rodriguez-Navarro C. (2019) Reaction of pseudowollastonite with carbonate-bearing fluids: Implications for $\mathrm{CO}_{2}$ mineral sequestration. Chem. Geol. 524, 158-173.

Morimoto, N. (1988). Nomenclature of pyroxenes. Miner. Petrol., 39, 55-76. 
1048

1049

1050

1051

1052

1053

1054

1055

1056

1057

1058

1059

1060

1061

1062

1063

1064

1065

1066

1067

1068

1069

1070

Morse J. W. and Bender M. L. (1990) Partition coefficients in calcite: Examination of factors influencing the validity of experimental results and their application to natural systems. Chem. Geol. 82, 265-277.

Mozgawa, W., Handke, M., \& Jastrzębski, W. (2004). Vibrational spectra of aluminosilicate structural clusters. J. Molec. Struct., 704, 247-257.

Nagajyoti P. C., Lee K. D. and Sreekanth T. V. M. (2010) Heavy metals, occurrence and toxicity for plants: A review. Environ. Chem. Lett. 8, 199-216.

O’Connor, W. K., Dahlin, D. C., Rush, G. E., Gerdemann, S. J., Penner, L. R., \& Nilsen, D. N. (2005). Aqueous mineral carbonation. Final Report-DOE/ARC-TR-04-002, Department of Energy, USA.

Oelkers, E. H., \& Cole, D. R. (2008). Carbon dioxide sequestration a solution to a global problem. Elements 4, 305-310.

Omori, K. (1971). Analysis of the infrared absorption spectrum of diopside. Am. Mineral., 56, 1607-1616.

Ott, H., Oedai, S. (2015). Wormhole formation and compact dissolution in single-and two-phase $\mathrm{CO}_{2}$-brine injections. Geophys. Res. Lett. 42, 2270-2276.

Pacala S. and Socolow R. (2004) Stabilization wedges: Solving the climate problem for the next 50 years with current technologies. Science 305, 968-972.

Park, A. H. A., \& Fan, L. S. (2004). $\mathrm{CO}_{2}$ mineral sequestration: physically activated dissolution of serpentine and pH swing process. Chem. Eng. Sci. 59, 5241-5247.

Parkhurst, D., \& Appelo, C. A. J. (2011). PHREEQC (Version 3)—A computer program for speciation, batch-reaction, one-dimensional transport, and inverse geochemical calculations. Water Resources Div., Denver, CO.

Plümper, O., Røyne, A., Magrasó, A. and Jamtveit, B. (2012). The interface-scale mechanism of reactioninduced fracturing during serpentinization. Geology, 40, 1103-1106.

Putnis A. (2009) Mineral replacement reactions. Rev. Mineral. Geochem. 70, 87-124. 
1071

1072

1073

1074

1075

1076

1077

1078

1079

1080

1081

1082

1083

1084

1085

1086

1087

1088

1089

1090

1091

1092

1093

Rajabipour, F., Giannini, E., Dunant, C., Ideker, J. H. and Thomas, M. D. (2015). Alkali-silica reaction: current understanding of the reaction mechanisms and the knowledge gaps. Cem. Concr. Res., 76, 130146.

Reinhardt, H. W. and Mielich, O. (2011). A fracture mechanics approach to the crack formation in alkalisensitive grains. Cem. Concr. Res., 41, 255-262.

Renard, F. and Ortoleva, P. (1997). Water films at grain-grain contacts: Debye-Hückel, osmotic model of stress, salinity, and mineralogy dependence. Geochim. Cosmochim. Acta 61, 1963-1970.

Rietveld H. M. (1969) A profile refinement method for nuclear and magnetic structures. J. Appl. Crystallogr. $2,65-71$.

Rodriguez-Navarro C., Kudlacz K., Cizer O. and Ruiz-Agudo E. (2015) Formation of amorphous calcium carbonate and its transformation into mesostructured calcite. CrystEngComm 17, 58-72.

Røyne A. and Jamtveit B. (2015) Pore-scale controls on reaction-driven fracturing. Rev. Mineral. Geochem. 80, $25-44$.

Ruiz-Agudo E., King H. E., Patiño-López L. D., Putnis C. V, Geisler T., Rodriguez-Navarro C. and Putnis A. (2016) Control of silicate weathering by interface-coupled dissolution-precipitation processes at the mineral-solution interface. Geology 44, 567-570.

Ruiz-Agudo E., Putnis C. V., Rodriguez-Navarro C. and Putnis A. (2012) Mechanism of leached layer formation during chemical weathering of silicate minerals. Geology 40, 947-950.

Scherer G. W. (1999) Crystallization in pores. Cem. Concr. Res. 29, 1347-1358.

Scherer G.W. (2004) Stress from crystallization of salt. Cem. Concr. Res. 34, 1613-1624.

Schiro M., Ruiz-Agudo E. and Rodriguez-Navarro C. (2012) Damage mechanisms of porous materials due to in-pore salt crystallization. Phys. Rev. Lett. 109, 265503.

Schott J., Berner R. A. and Sjöberg E. L. (1981) Mechanism of pyroxene and amphibole weathering-I. 
1095

1096

1097

1098

1099

1100

1101

1102

1103

1104

1105

1106

1107

1108

1109

1110

1111

1112

1113

1114

1115

1116

Schott J., Pokrovsky O. S., Spalla O., Devreux F., Gloter A. and Mielczarski J. A. (2012) Formation, growth and transformation of leached layers during silicate minerals dissolution: The example of wollastonite. Geochim. Cosmochim. Acta 98, 259-281.

Schwertmann U. (1991) Solubility and dissolution of iron oxides. Plant Soil 130, 1-25.

Seifritz W. (1990) $\mathrm{CO}_{2}$ disposal by means of silicates. Nature 345, 486.

Siever R. and Woodford N. (1979) Dissolution kinetics and the weathering of mafic minerals. Geochim. Cosmochim. Acta 43, 717-724.

Steiger M. (2005) Crystal growth in porous materials-I: The crystallization pressure of large crystals. $J$. Cryst. Growth 282, 455-469.

Sissmann O., Daval D., Brunet F., Guyot F., Verlaguet A., Pinquier Y., Findling N. and Martinez I. (2013) The deleterious effect of secondary phases on olivine carbonation yield: Insight from time-resolved aqueous-fluid sampling and FIB-TEM characterization. Chem. Geol. 357, 186-202.

Stockmann G., Wolff-Boenisch D., Gislason S. R. and Oelkers E. H. (2008) Dissolution of diopside and basaltic glass: the effect of carbonate coating. Mineral. Mag. 72, 135-139.

Stockmann G. J., Wolff-Boenisch D., Gislason S. R. and Oelkers E. H. (2013) Do carbonate precipitates affect dissolution kinetics?: 2: Diopside. Chem. Geol. 337, 56-66.

Tada H., Paris P. C. and Irwin, G. R. (2000). The stress analysis of cracks handbook (Vol. 130). New York: ASME press.

Urey H. C. (1952). The planets: their origin and development. In Mrs. Hepsa Ely Silliman Memorial Lectures, Yale University, London: Cumberlege.

Van Pham T. H., Aagaard P. and Hellevang H. (2012) On the potential for $\mathrm{CO}_{2}$ mineral storage in continental flood basalts-PHREEQC batch-and 1D diffusion-reaction simulations. Geochem. Trans. 

13,5 .

1118

1119

1120

1121

1122

1123

1124

1125

1126

1127

1128

1129

1130

1131

1132

1133

1134

1135

1136

1137

Van Noort, R., Wolterbeek, T. K., Drury, M. R., Kandianis, M. T., \& Spiers, C. J. (2017). The force of crystallization and fracture propagation during in-situ carbonation of peridotite. Minerals 7, 190.

Walker, J. C., Hays, P. B., \& Kasting, J. F. (1981). A negative feedback mechanism for the long-term stabilization of Earth's surface temperature. J. Geophys. Res. Oceans 86, 9776-9782.

Whitney, D. L., Broz, M., \& Cook, R. F. (2007). Hardness, toughness, and modulus of some common metamorphic minerals. Am. Mineral. 92, 281-288.

Wild B., Daval D., Micha J.-S., Bourg I. C., White C. E. and Fernandez-Martinez A. (2019) Physical properties of interfacial layers developed on weathered silicates: A case study based on labradorite feldspar. J. Phys. Chem. C. 123, 24520-24532.

Zheng, X., Cordonnier, B., Zhu, W., Renard, F. and Jamtveit, B. (2018). Effects of confinement on reaction-induced fracturing during hydration of periclase. Geochem. Geophys. Geosys. 19, 2661-2672.

Zhu, W., Fusseis, F., Lisabeth, H., Xing, T., Xiao, X., De Andrade, V. and Karato, S. I. (2016). Experimental evidence of reaction-induced fracturing during olivine carbonation. Geophys. Res. Lett. 43, 9535-9543. 

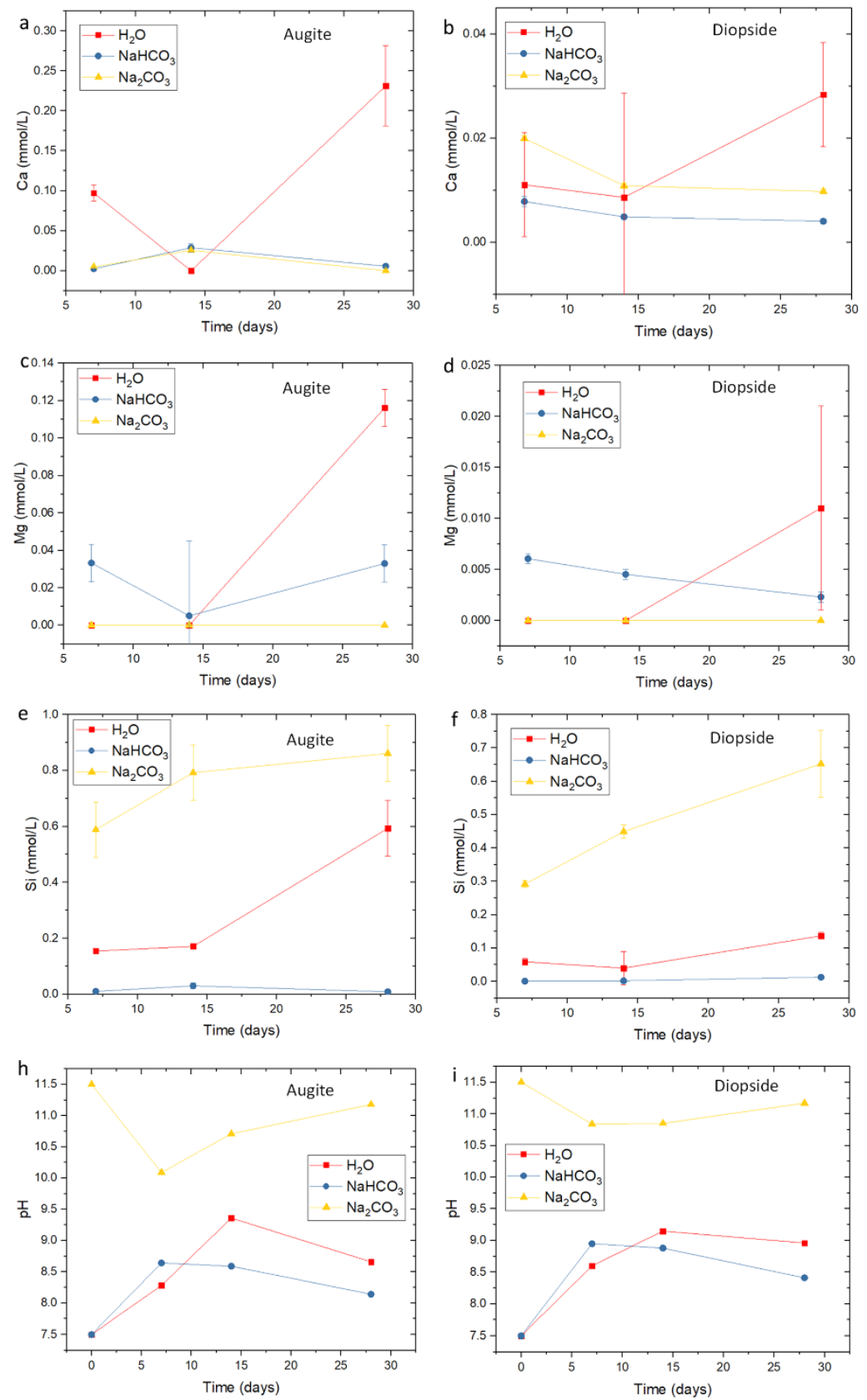

1140 Figure 1. Chemistry of solutions during augite and diopside dissolution and carbonation. Error bars show standard deviation of both replicas. Total concentration of aqueous calcium (a), magnesium (c) and silicon (e) in augite experiments; Total concentration of aqueous calcium (b), magnesium (d) and silicon (f) in diopside experiments; $\mathrm{pH}$ of augite (h) and diopside (i) experiments. Solid 1144 lines are used as a guide to the eye. 

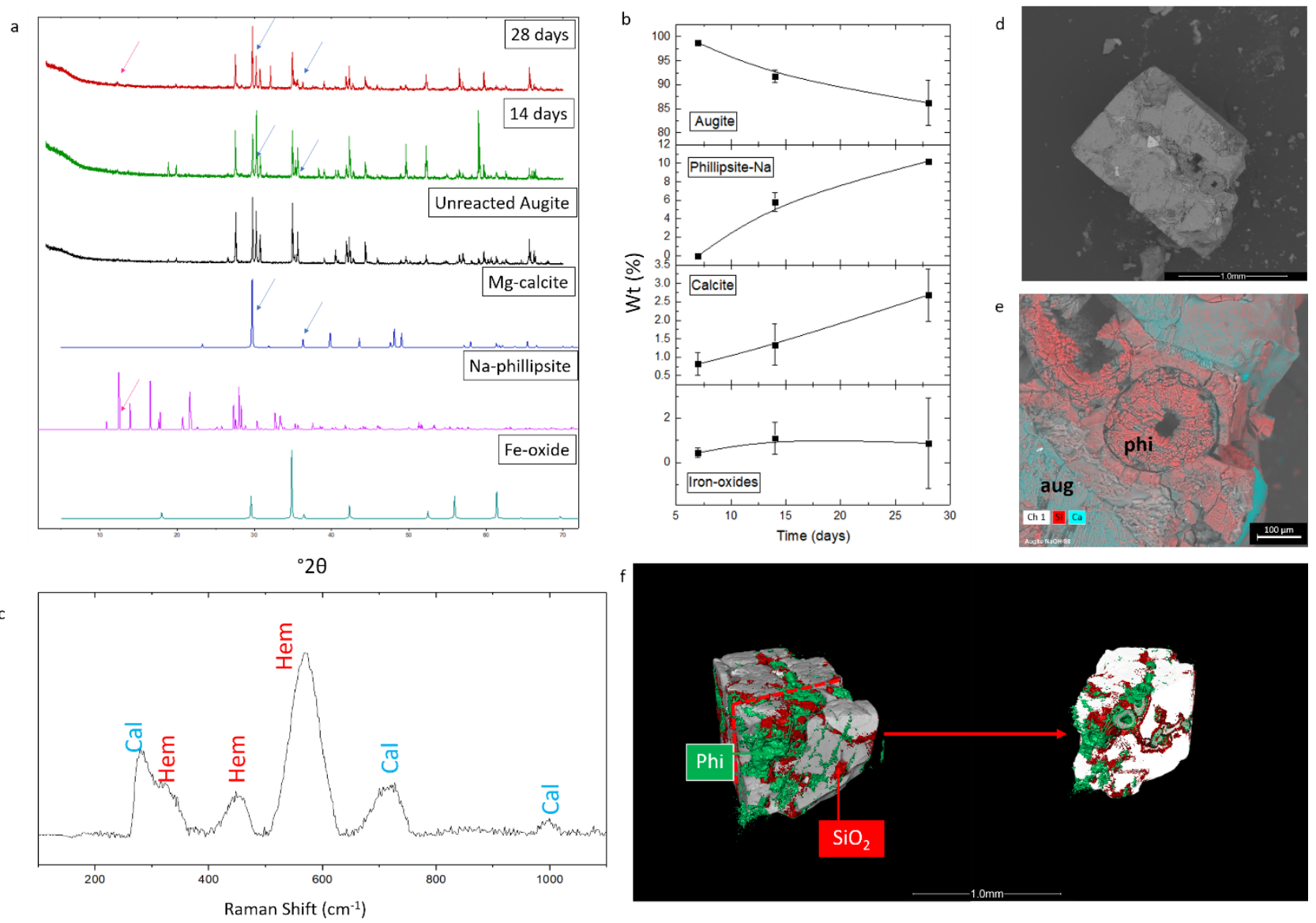

1148 Figure 2. Products of the reaction of augite in water ( $\mathrm{pH} 7.5)$ : (a) XRD patterns of reacted augite, 1149 unreacted augite and reference phases (Mg-calcite, Na-phillipsite and Iron Oxide) . (b) Time evolution of crystalline phases content determined by XRD Rietveld analyses (Error bars show standard deviation of both replicas). (c) $\mu$-Raman spectra of precipitated calcite (cal, blue) and hematite (hem, red) crystals. (d) Low-magnification SEM image of augite crystal after 28 days reaction. (e) SEM image overlaid with EDS compositional map showing a detail of the augite (aug) crystal fractured after 28 days reaction, with Na-phillipsite (phi) filling the fractures. (f) Micro-CT image showing in red the 3D distribution of amorphous silica $\left(\mathrm{SiO}_{2}\right)$ and in green the Na-phillipsite (phi) in augite crystal after 28 days reaction. The red dashed line in the left image represents the virtual cut performed to observe the interior of the newly-formed filled fracture, shown in the right image 

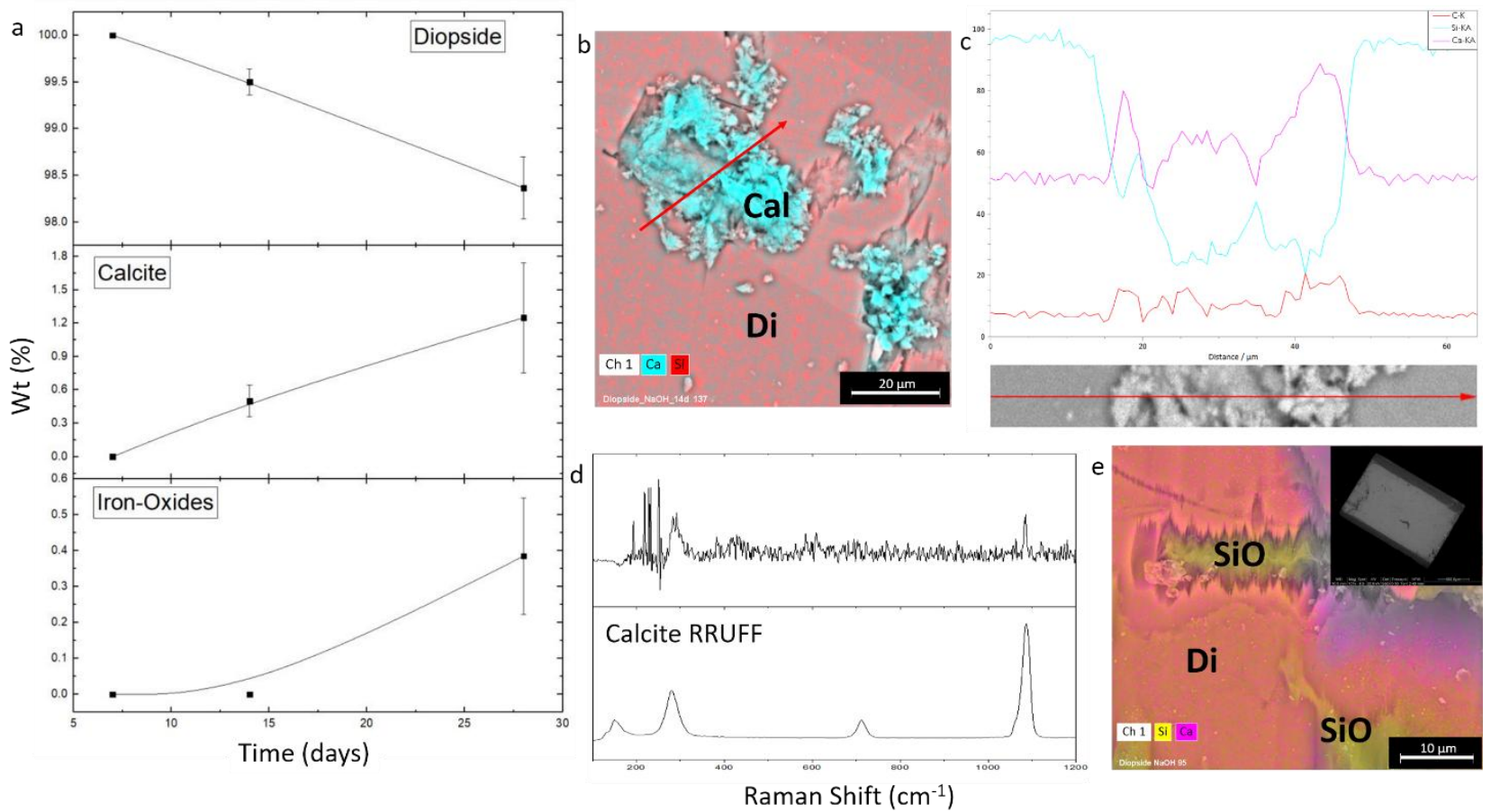

Figure 3. Products of the reaction of diopside in water $(\mathrm{pH} \mathrm{7.5):} \mathrm{(a)} \mathrm{Time} \mathrm{evolution} \mathrm{of} \mathrm{the}$ crystalline phases content determined by XRD Rietveld analysis (error bars show standard deviation). (b) SEM-EDS compositional map showing calcite (Cal) crystals in the dissolution pits of diopside (Di) after 14 days reaction. (c) SEM image and EDS compositional variation of Ca, Si and $\mathrm{C}$ along the red line in (b). (d) $\mu$-Raman spectra of calcite crystal formed on our experiment, along with that of calcite reference (RRUFF database). (e) SEM-EDS compositional map showing diopside (Di) after 28 days of reaction including a Si-bearing phase $\left(\mathrm{SiO}_{2}\right)$ inside a dissolution pit and on the surface of the pyroxene. The inset shows the SEM image of the reacted diopside crystal. 

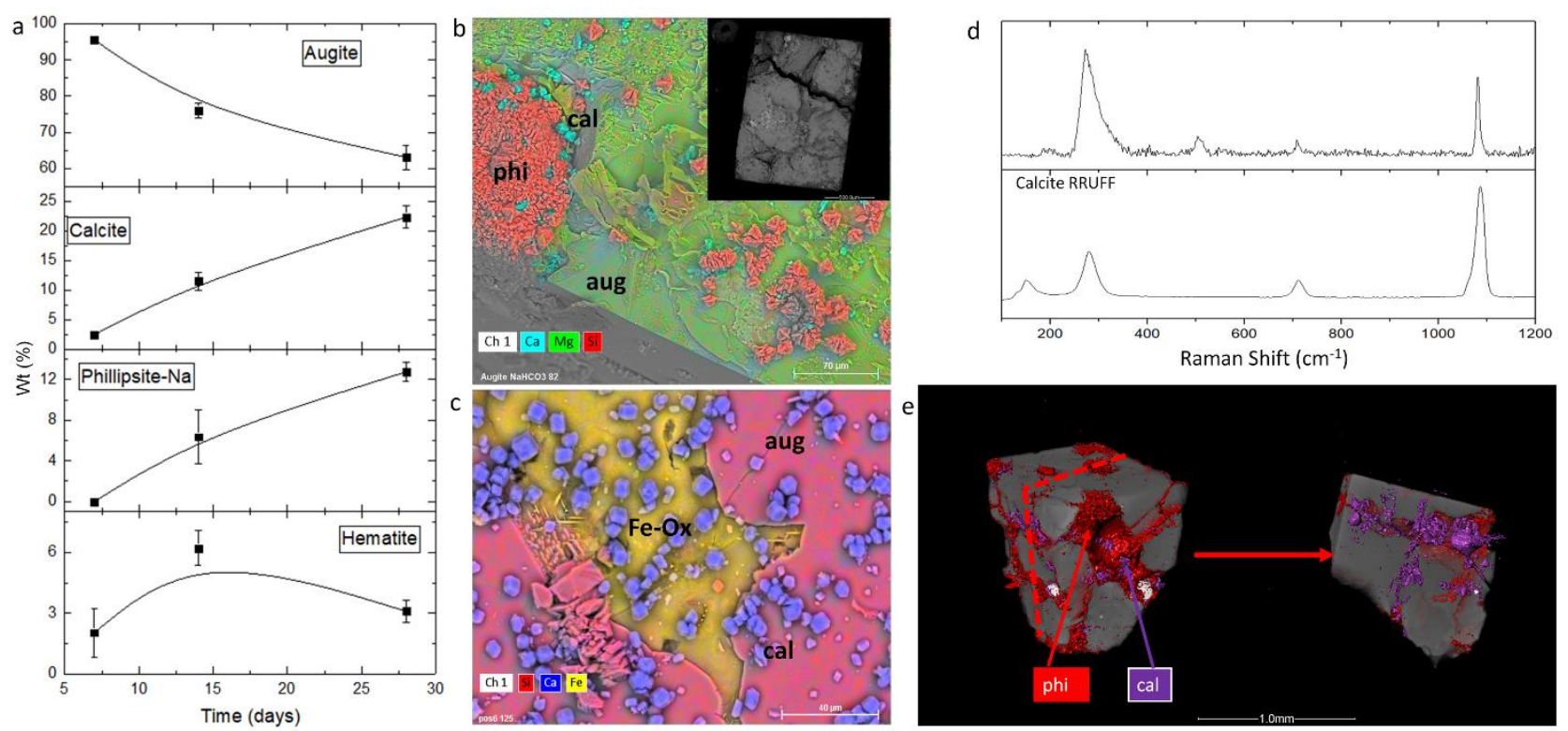

1187 Figure 4. Products of the reaction of augite in $\mathrm{NaHCO}_{3}$ solution: (a) Time evolution of the 1188 crystalline phases content determined by XRD Rietveld analysis (error bars show StDev). (b) SEM 1189 image of augite (aug) crystal after 28 days of reaction, overlaid with EDS compositional map showing phillipsite (phi) and a few crystals of calcite (cal) inside the fractures and on the augite surface. The inset shows the SEM image of the reacted crystals displaying pervasive craking. (c) SEM-EDS compositional map showing calcite (cal) crystals on the surface of augite (aug) and iron oxides (Fe-Ox) in dissolution areas. (d) $\mu$-Raman spectra of newly formed calcite (the spectra of reference calcite -RRUFF database- is also shown). (e) Micro-CT image showing in red the 3D distribution of phillipsite (phi) and in purple that of calcite (cal) in an augite crystal after 28 days of reaction. The red dotted line on the left image represents the virtual cut displayed on the right image. 

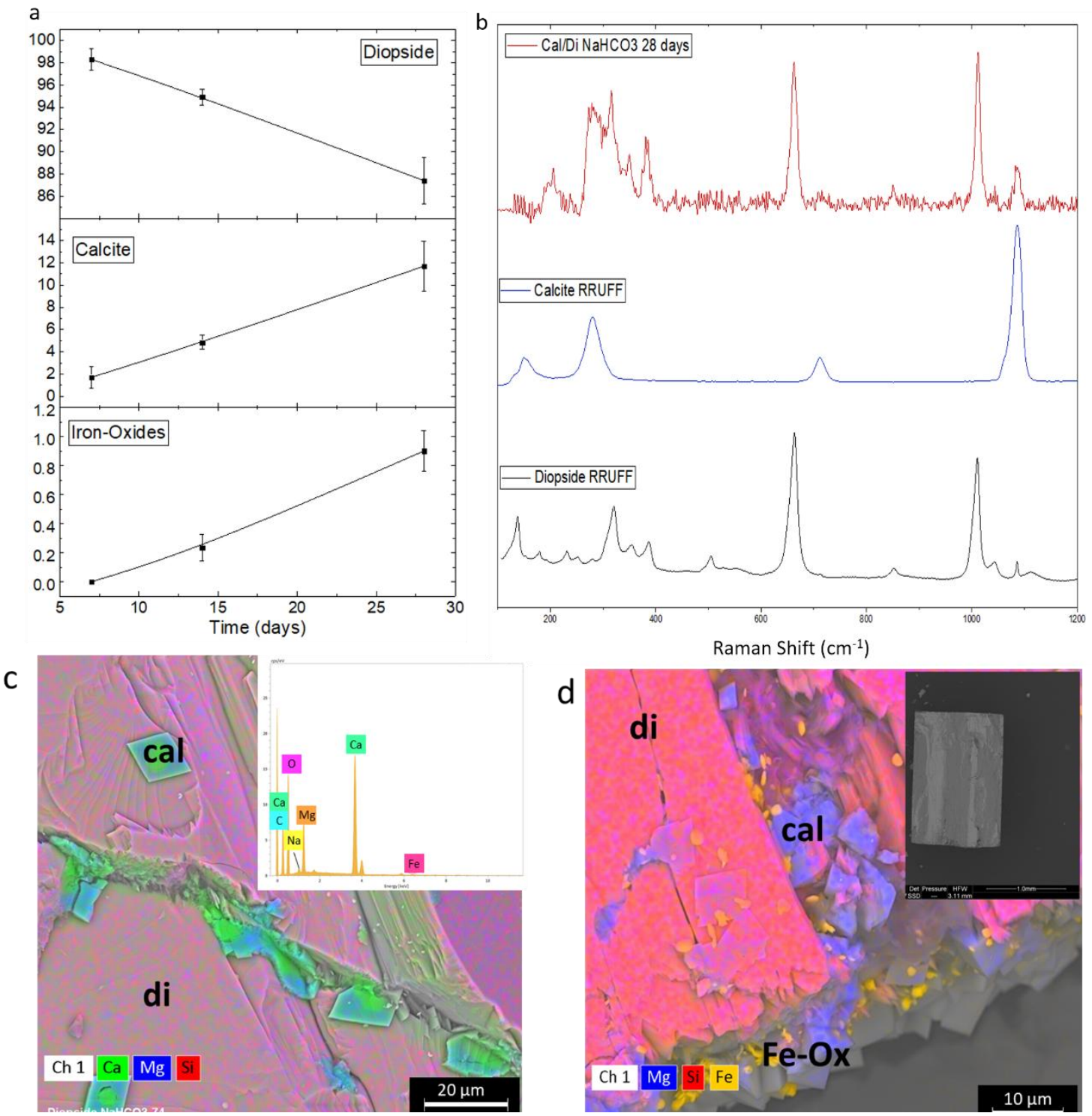

1205 Figure 5. Products of the reaction of diopside in $\mathrm{NaHCO}_{3}$ solution: (a) Time evolution of the crystalline phases determined by XRD Rietveld analyses (error bars show StDev). (b) $\mu$-Raman spectra of calcite crystal formed after 28 days reaction (labeled $\mathrm{Cal} / \mathrm{Di}$ ), along with reference spectra (RUFF database) of calcite and diopside for comparison. (c) SEM-EDS compositional map showing magnesium calcite crystals (cal) and diopside (di) after 28 days of reaction. EDS spectra of Mg-calcite in inset. (d) SEM-EDS compositional map showing calcite (cal) crystals inside the fractures of the diopside (di) and iron-oxide particles on the surface (Fe-Ox). The inset shows the reacted pyroxene crystal. 

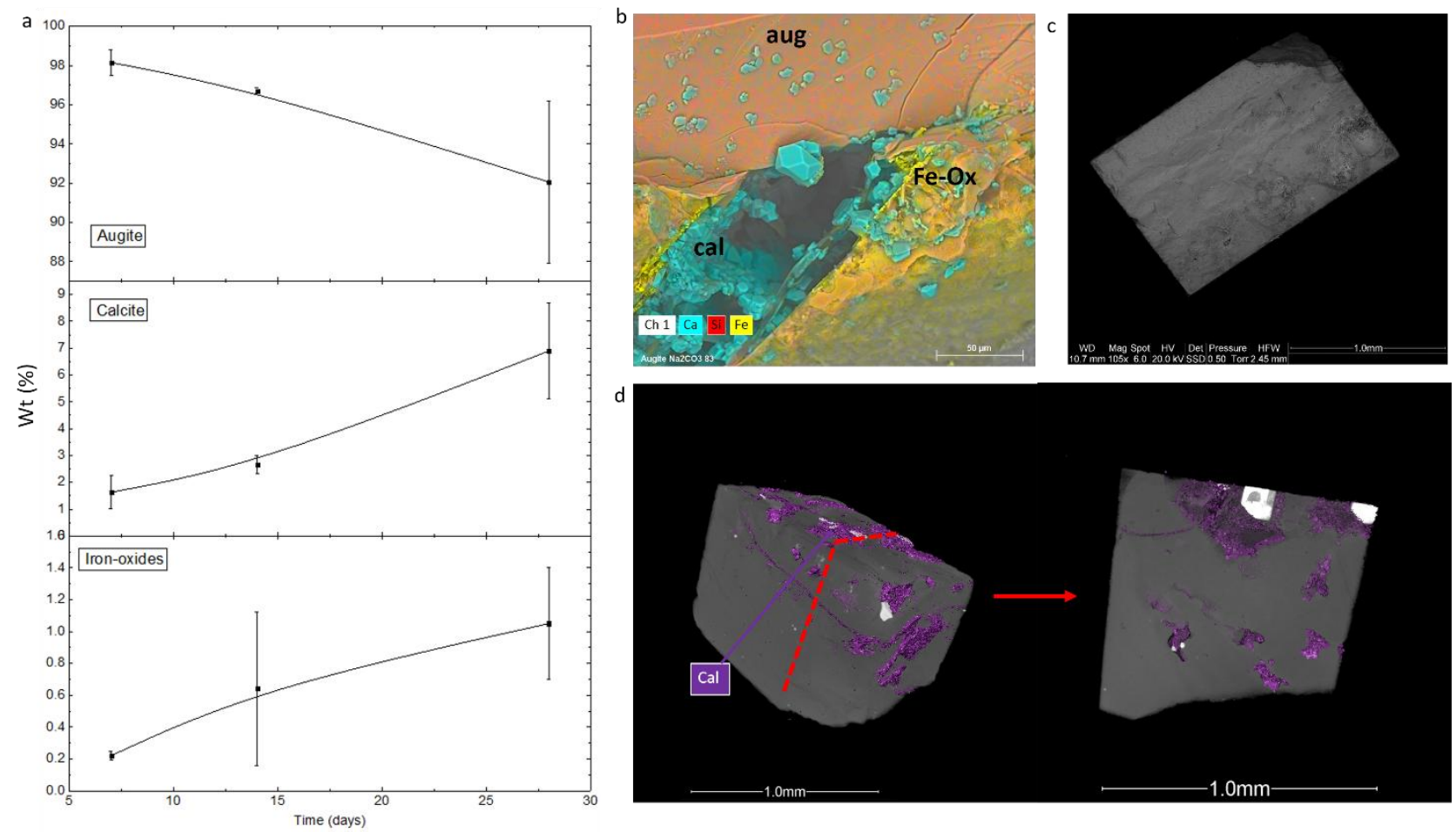

Figure 6. Products of the reaction of augite in $\mathrm{Na}_{2} \mathrm{CO}_{3}$ solution: (a) Time evolution of the crystalline phases content determined by XRD Rietveld analyses (error bars show StDev). (b) SEMEDS compositional map of 28 days reacted augite (aug) showing calcite (cal) crystals inside (preexisting) surface fractures and iron oxides (Fe-Ox) lining the fracture walls. (c) SEM image of the entire crystal after reaction. (d) Micro-CT image showing the 3D distribution of calcite (purple) in augite crystal after 28 days of reaction. The red dashed line in the left image represents the virtual cut performed to observe the inside of the crystal, shown in the right image. Note: the white bright inclusions are rutile (detected by XRD). 

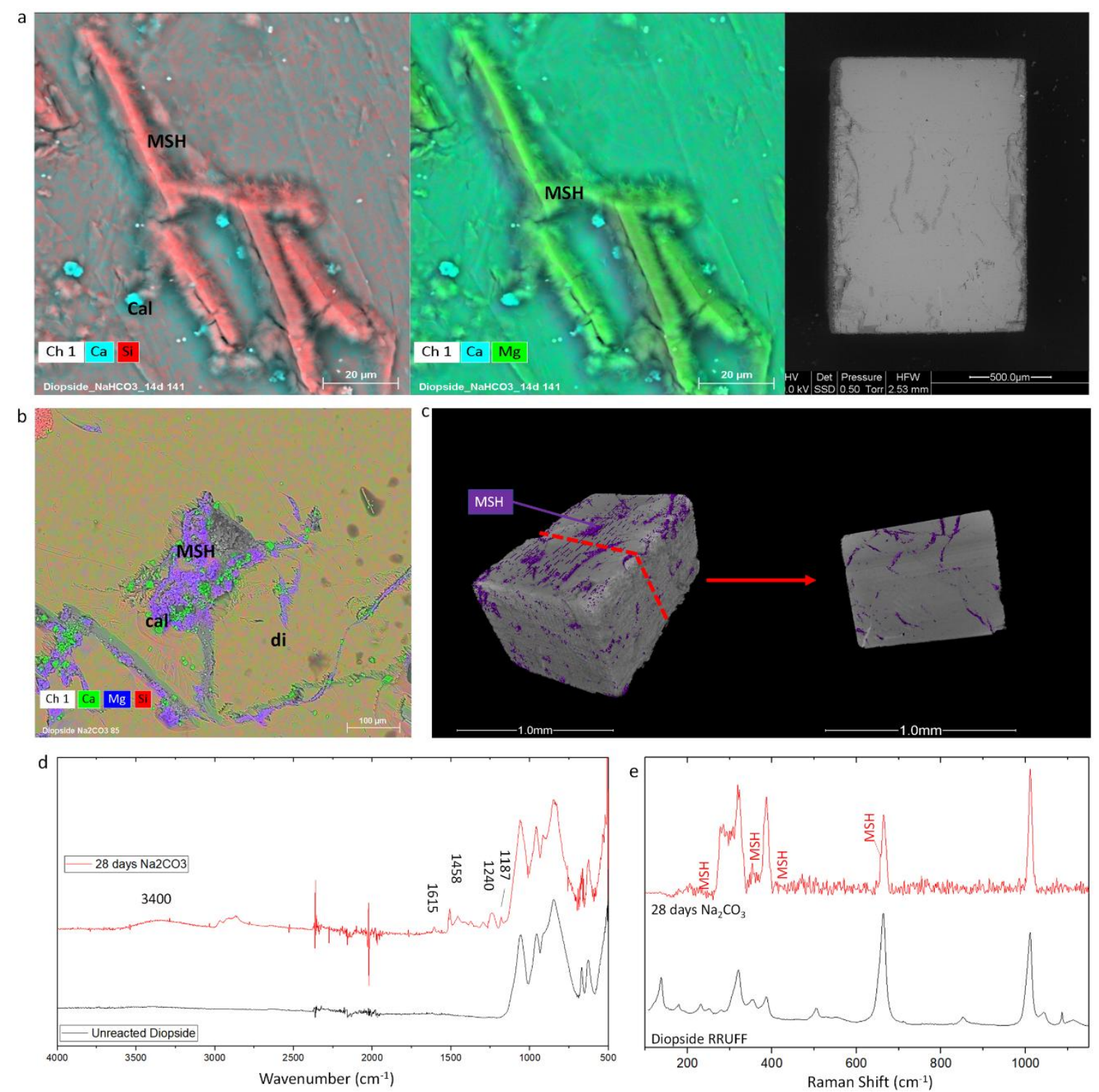

Figure 7. Products of the reaction of diopside in $\mathrm{Na}_{2} \mathrm{CO}_{3}$ solution: (a) SEM-EDS compositional map showing a proto magnesium silicate hydrate $(\mathrm{MSH})$ and calcite particles (cal) on the surface of diopside (di). The right SEM image shows the entire crystal after reaction. (b) SEM-EDS compositional map showing MSH in the dissolution pits and fractures of diopside (di) with calcite crystals (cal). (c) Micro-CT image showing the 3D distribution of MSH (red) and calcite (purple) in diopside crystal after 28 days of reaction. The red dashed line in the left image represents the virtual cut performed to observe the inside of the crystal, shon on the right image. (d) FTIR spectra of the diopside before and after 28 days reaction in $\mathrm{Na}_{2} \mathrm{CO}_{3}$ solution. (f) $\mu$-Raman spectra of the diopside reacted 28 days in $\mathrm{Na}_{2} \mathrm{CO}_{3}$ solution showing the bands corresponding to MSH (Lothenbatch et al., 2015) and the spectrum of diopside from RRUFF database. 


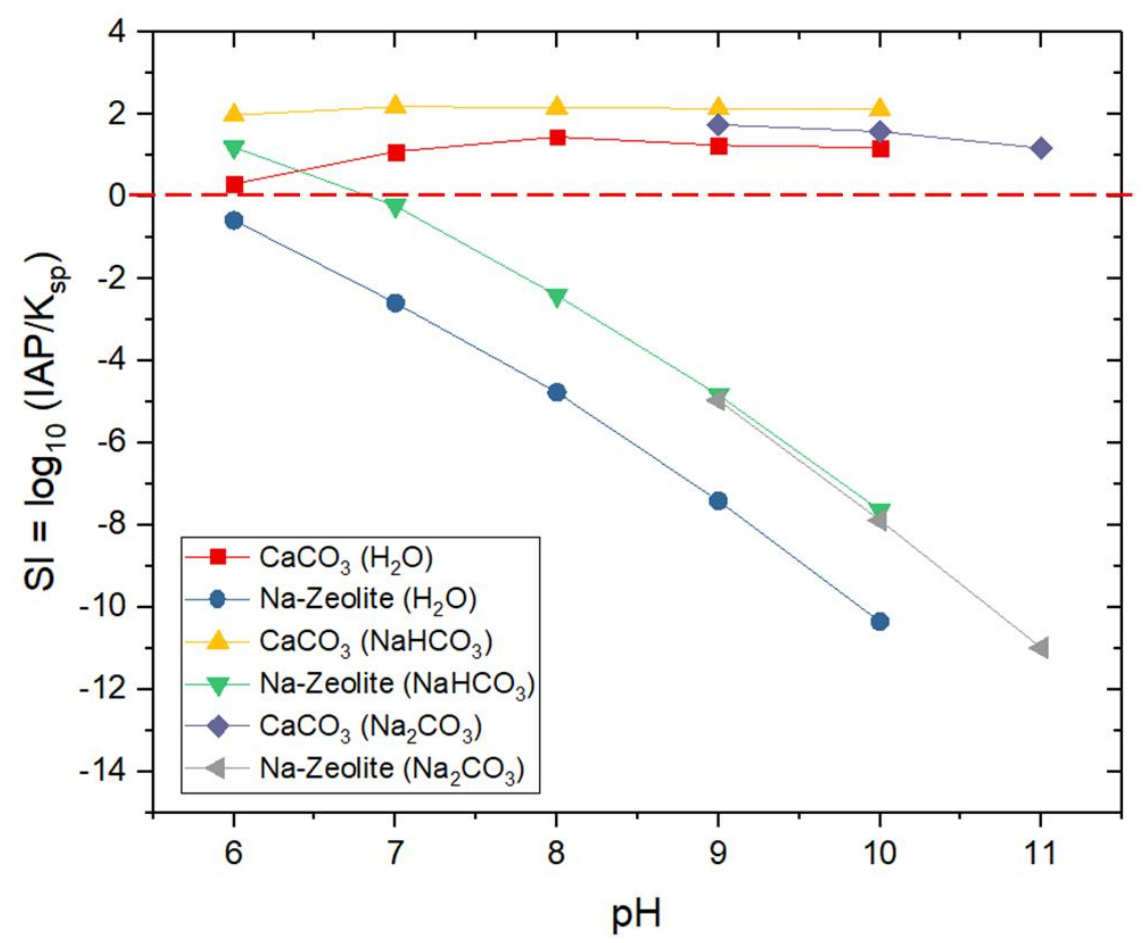

1251 Figure 8. PHREEQC simulations of saturation index (SI) evolution vs. pH for calcite and sodium 1252 zeolite during augite mineral replacement reaction at equilibrium. The red dashed line represents 1253 equilibrium (i.e., $\mathrm{SI}=0$ ). 
a
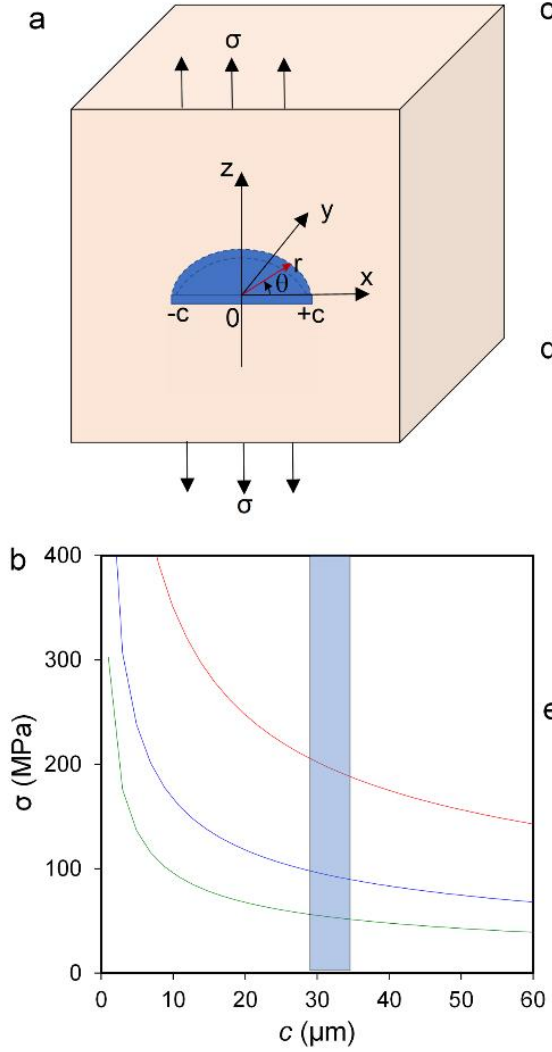
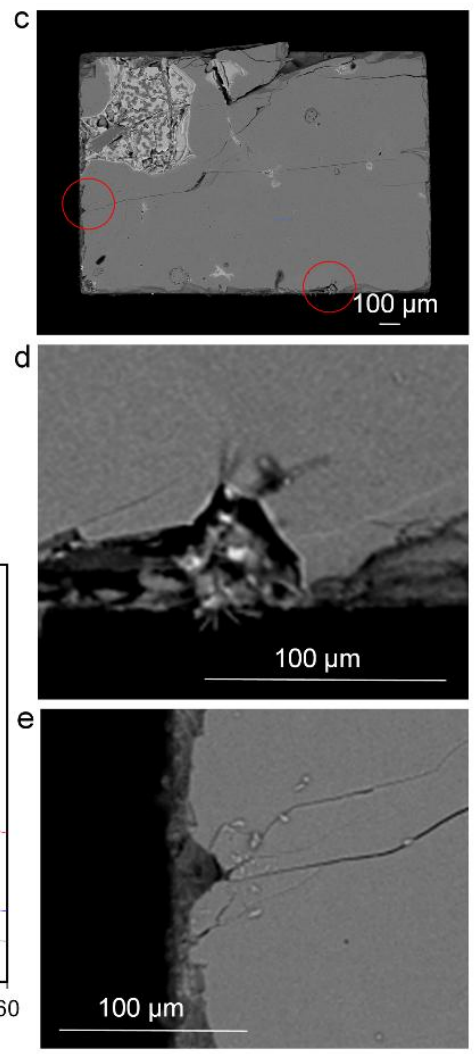

1261

Figure 9. Fracture mechanics of carbonated augite crystals. (a) Scheme of the case of a semicircular flaw normal to the face exposed to the solution of a solid of semi-infinite length undergoing internal pressurization ( $\sigma=$ stress; $\theta=$ angle between the flaw plane and the xz plane; $\mathrm{r}=$ radius of the flaw). (b) Critical stress $(\sigma)$ for fracture opening vs. $c$ (flaw radius) for different values of augite fracture toughness (green curve $=0.35 \mathrm{MPa} \mathrm{m}^{1 / 2}$, blue curve $=0.61 \mathrm{MPa} \mathrm{m}^{1 / 2}$, and red curve $=1.28$ $\left.\mathrm{MPa} \mathrm{m}^{1 / 2}\right)$. The blue-shaded vertical bar marks the average depth $( \pm \mathrm{SD})$ of etch pits (i.e., flaw radius $c$ in (a)) in augite filled with Na-phillipsite. (c) SEM image of augite subjected to 7 days reaction in $\mathrm{NaHCO}_{3}$ solution showing etch pits (red circles) where cracks are formed at their tips. (d) Detail of an etch pit filled with Na-Phillipsite, showing a crack originating at the pit tip. (e) Detail of cracks emerging from the tip of an etch pit filled with Na-Phillipsite. 
1281 Table 1. Results of the quantitative Rietveld analysis (wt\%) after normalization to amorphous phase 1282 content determined using mass balance analysis. Data for pyroxene samples after 28 days of 1283 reaction. The last two columns report the extent of carbonation (i.e., mass fraction of pyroxene 1284 converted into calcium carbonate) calculated using Rietveld refinement $\left(\xi \mathrm{n}^{\mathrm{RR}}\right)$ and mass balance $1285\left(\xi n^{\mathrm{MB}}\right)$.

Reactant Augite Diopside Phillipsite-Na Hematite Calcite $\mathrm{SiO}_{2} \mathrm{MSH} \xi_{\mathrm{n}}{ }^{\mathrm{RR}} \xi_{\mathrm{n}}^{\mathrm{MB}}$

\begin{tabular}{ccccccccc}
\hline Water & 83.97 & & 9.86 & 0.85 & 2.61 & 2.16 & 0.0016 & 0.0018 \\
$\mathrm{NaHCO}_{3}$ & 61.93 & & 12.39 & 2.01 & 21.71 & 2.09 & 0.1669 & 0.1842 \\
$\mathrm{Na}_{2} \mathrm{CO}_{3}$ & 96.34 & & 0 & 1.05 & 2.65 & & 0.0131 & 0.0147 \\
\hline Water & & 96.73 & & 0.37 & 1.23 & 1.62 & 0.0004 & 0.0004 \\
$\mathrm{NaHCO}_{3}$ & 86.32 & & 0.81 & 11.5 & 1.27 & 0.0328 & 0.0379 \\
$\mathrm{Na}_{2} \mathrm{CO}_{3}$ & 93.09 & & & 2.13 & & 5.01 & 0.0011 & 0.0012 \\
\hline
\end{tabular}

1293 Table 2. Free energy $\left(\mathrm{kJ}^{\mathrm{m}} \mathrm{mol}^{-1}\right)$ values for all experiments calculated using PREEQC and 1294 experimental values obtained by ICP-OES of the ionic concentration in solution and measured $\mathrm{pH}$ 1295 after each experiment. 


\begin{tabular}{|c|c|ccc|}
\hline \multicolumn{2}{|c|}{} & \multicolumn{3}{|c|}{ Time (days) } \\
\hline Mineral & Reactant & 7 & 14 & 28 \\
\hline \multirow{3}{*}{ Diopside } & Water & -39.37 & -45.93 & -6.16 \\
& NaHCO3 & -61.49 & -64.08 & -59.06 \\
& Na2CO3 & -20.17 & -28.11 & -157.65 \\
\hline & & & & \\
\hline \multirow{4}{*}{ Augite } & Water & -43.99 & -51.28 & -16.28 \\
& NaHCO3 & -74.04 & -84.90 & -80.61 \\
& Na2CO3 & -38.64 & -46.50 & -179.52 \\
\hline
\end{tabular}

1296

1297 